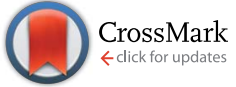

Cite this: RSC Adv., 2015, 5, 40205

\title{
A family of unsymmetrical hydroxyl-substituted BEDT-TTF donors: syntheses, structures and preliminary thin film studies $\uparrow$
}

\author{
Qiang Wang, ${ }^{\text {ab }}$ Matteo Zecchini, ${ }^{c}$ John D. Wallis, ${ }^{c}$ Yiliang Wu, de Jeremy M. Rawson ${ }^{f}$ \\ and Melanie Pilkington ${ }^{\star a}$
}

Three new unsymmetrical hydroxyl-functionalized donors $\mathrm{H} 1-\mathrm{H} 3$ closely related to hydroxymethyl-BEDTTTF have been synthesised and characterised. Cyclic voltammetry studies showed that the compounds exhibit reversible two one-electron redox processes typical for BEDT-TTF derivatives. X-ray diffraction studies of $\mathrm{H} 1$ and $\mathrm{H} 2$ reveal $\pi$-stacking interactions between pairs of donors that are organized into distinct $\mathrm{H}$-bonded square motifs and DFT calculations indicate that the HOMO is located on the central 1,3-dithiole rings. Protection of the hydroxyl group with acetyl in 13 eliminates co-facial S $\cdots S$ interactions between the dimers to accommodate the bulkier side chains, but short edge-to-edge $S \cdots S$ contacts offer an alternative pathway for electron mobility. Chemical oxidation of $\mathrm{H} 1$ and HMET 2 with $\mathrm{I}_{2}$ afforded single crystals of two $1: 1$ charge transfer salts, 18 and 19. The molecules pack as dimers with close $\pi$-stacking interactions between pairs of radical cations whose crystal structures are further stabilized via an interplay of S $\cdots S$ and $S \cdots \mid$ contacts. lodine-doped surface conducting polystyrene blend films of $\mathrm{H} 3$ deposited on a silica substrate exhibit quasiconducting properties, but afford no OFET response when fabricated into devices. Visible-NIR studies of a doped polystyrene blend film of $\mathrm{H} 3$ cast on a glass substrate show absorption bands at $\lambda=950$ and $3000 \mathrm{~nm}$, consistent with mixed valence states due to the presence of charge-transfer species on the surface of the films.

Received 15th March 2015

Accepted 13th April 2015

DOI: $10.1039 / c 5 r a 04568 a$

www.rsc.org/advances

\section{Introduction}

First used to prepare an organic metal in the 1970 's, ${ }^{1}$ tetrathiafulvalene (TTF) and its derivatives now represent one of the most well studied classes of sulfur containing heterocycles of interest to main group, organic, supramolecular and materials chemists worldwide. ${ }^{2}$ In more recent years this family of compounds have found applications as molecular switches ${ }^{3}$ shuttles and sensors, ${ }^{4}$ as well as redox accessible organic donors for the preparation of conducting radical cation salts. ${ }^{5}$ The

\footnotetext{
${ }^{a}$ Department of Chemistry, Brock University, 500 Glenridge Avenue, Ontario, L2S 3A1, Canada.E-mail: mpilkington@ubrock.ca

${ }^{b}$ School of Chemistry and Chemical Engineering, Wuhan Textile University, Wuhan, 430073, China

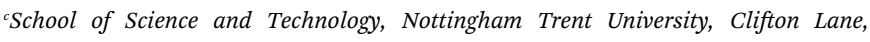
Nottingham, NG11 8NS, UK

${ }^{d}$ Xerox Research Centre of Canada, 2660 Speakman Drive, Mississauga, ON, L5K 2L1, Canada

${ }^{e}$ Corporate Technology, TE Connectivity, 306 Constitution Drive, Menlo Park, CA, 94025, USA

${ }^{f}$ Department of Chemistry and Biochemistry, University of Windsor, 401 Sunset Ave., Windsor, Ontario, N9B 3P4, Canada

$\dagger$ Electronic supplementary information (ESI) available. CCDC 1052024-1052028. For ESI and crystallographic data in CIF or other electronic format see DOI: 10.1039/c5ra04568a
}

driving force in the crystallization of the salts are their strong $\pi-\pi$ stacking interactions that, together with $\mathrm{C}-\mathrm{H} \cdots \mathrm{S}$ and $\mathrm{S} \cdots \mathrm{S}$ contacts, facilitate the intermolecular electronic transfer responsible for their transport properties. Until fairly recently conducting salts of TTFs were prepared as single crystals with mobilities exceeding $10 \mathrm{~cm}^{2} \mathrm{~V}^{-1} \mathrm{~s}^{-1}$ for modified derivatives with side chains. Although crystalline radical cation salts have found applications in the field of organic electronics, ${ }^{6}$ attention has been more recently focused on developing more soluble derivatives for solution-processable technologies. ${ }^{7}$ One clear advantage of this approach is that it affords tuneable materials that combine the unique electronic properties of molecular metals (e.g. metallic conductivity) together with the favourable properties of a polymeric matrix for applications where lowcost, large-area coverage and flexibility are important considerations.

In contrast to TTF, the chemistry of bis(ethylenedithio)tetrathiafulvalene, more commonly known as BEDT-TTF or ET, has been much less well explored even though it has played a prominent role in the development of molecular conductors, superconductors, and bifunctional materials. ${ }^{8}$ Although formation of conducting films of BEDT-TTF have been studied, ${ }^{9}$ reports of films prepared from its substituted derivatives are restricted to the formation of LB films from hexadecyl-(BEDTTTF), and its combination with hexadecyl-TCNQ, or reaction 
<smiles>CC(F)S1=C2SC=CSC2=CS1</smiles>
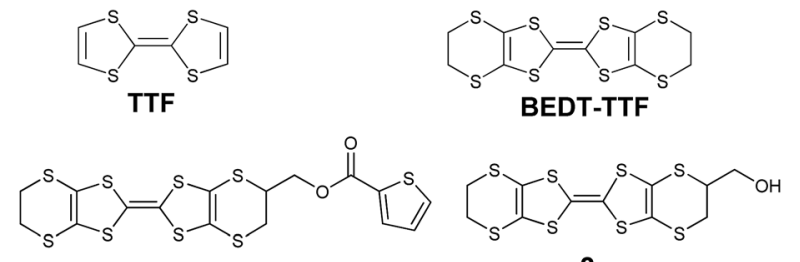

1

\section{2}

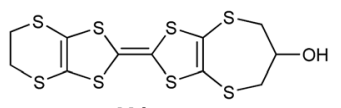

H1

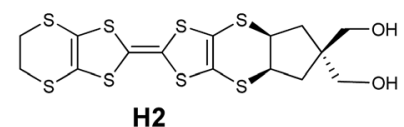

$\mathrm{H} 2$

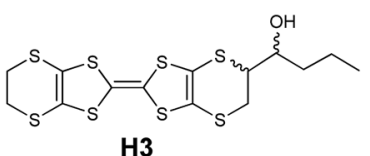

Fig. 1 Molecular structures of TTF, BEDT-TTF, the thiophene appended donor 1 , HMET 2 and the hydroxyl donors $\mathrm{H} 1-\mathrm{H} 3$.

with Fe(III). ${ }^{10}$ Related studies have also involved deposition of a mercaptodecylthio-(EDT-TTF) derivative onto a mica supported gold surface, ${ }^{\mathbf{1 1}}$ and hydroxymethyl substituted EDT-TTF derivatives have been combined with arachidonic acid to form weakly conducting Langmuir-Blodgett films. ${ }^{\mathbf{1 2}}$

Over the last two decades our research program has predominantly focused on developing synthetic methodologies for the preparation of new families of BEDT-TTF derivatives, particularly chiral donors. ${ }^{13}$ In more recent years we have shifted our attention to establish libraries of organic donors whose electronic properties and solubilities can be tuned via molecular design to render them suitable for a particular electronic application. In this context we recently reported the electronic properties of thin films prepared from thiophene appended BEDT-TTF derivatives e.g. 1 for applications as organic field effect transistors (OFETs). ${ }^{14}$ In this new study we report the synthesis and study of a new family of unsymmetrical hydroxylsubstituted donors H1-H3, the $O$-acetyl protected intermediate 13, and the previously reported hydroxymethyl BEDT-TTF $2^{13 d}$ (Fig. 1). Hydrogen bonds are one of the fundamentally important non-covalent interactions in chemistry and biology that have also recently been shown to play a role in the switching of conductivity and magnetism in a TTF derivative. ${ }^{15}$ Our objectives were two fold; firstly to introduce hydroxyl substituents into the molecular framework of the BEDT-TTF donor to optimize the number and type of intermolecular interactions, increase the dimensionality of the materials and thus improve their charge transport properties; secondly, we set out to tune the solubility of the donors and establish experimental conditions for the preparation of solution processable thin films in order to evaluate their electrical properties and suitability for OFET applications.

\section{Experimental}

\section{General considerations}

All experiments were performed under a nitrogen atmosphere unless stated otherwise. Dry solvents were obtained from a
Puresolve PS MD-4 solvent purification system. ${ }^{1} \mathrm{H}$ and ${ }^{13} \mathrm{C}$ NMR spectra were recorded on Bruker AVANCE AV300 or AV600 NMR spectrometers and chemical shifts were determined with reference to residual solvent. IR spectra were recorded on a Mattson Research Series FT-IR spectrometer as KBr discs. EI and HR FAB mass spectrometry measurements were obtained from a KRATOS/MSI CONCEPT 1-S spectrometer. Accurate mass, nanoelectrospray measurements were obtained on an LTQ Oribtrap XL spectrometer. Elemental analyses were obtained from Atlantic Microlab. Melting points were measured on a SMP10 melting point apparatus. Cyclic voltammetry measurements were recorded at room temperature under $\mathrm{N}_{2}$ in a conventional three-electrode cell using Pt working electrodes (3 mm diameter), a Pt wire counter electrode, an $\mathrm{Ag} / \mathrm{AgCl}$ reference electrode and a BAS Epsilon potentiostat. Electronic absorption spectra were measured on a Varian 5000 UV-vis-NIR spectrophotometer. Fabricated OTFT devices were evaluated using a Keithley SCS-4200 characterization system under ambient conditions. Four-probe DC measurements were carried out on a Keithley 236 Source Measurement Unit. HMET was prepared according to literature procedures. ${ }^{13 \boldsymbol{d}}$ Experimental details for the synthesis of the $O$-acetyl protected compounds 7 , $\mathbf{1 3}$ and $\mathbf{1 7}$ together with donors $\mathbf{H 1}$ to $\mathbf{H 3}$ are presented in the text. Full experimental procedures for the preparation of all synthetic intermediates are provided in S-1 of the ESI. $\dagger$

\section{Synthesis of (2-acetoxypropylene-1,3-dithio)(ethylenedithio) tetrathiafulvalene $(7)$}

A suspension of oxo compound $5(0.70 \mathrm{~g}, 2.50 \mathrm{mmol})$ and unsubstituted thione $6(1.12 \mathrm{~g}, 5.00 \mathrm{mmol})$ in dry triethyl phosphite $(5 \mathrm{~mL})$ was heated to $90{ }^{\circ} \mathrm{C}$ under nitrogen for $16 \mathrm{~h}$. The mixture was cooled to room temperature and hexane $(10 \mathrm{~mL})$ was added to facilitate further precipitation. The solid was collected and washed with hexane $(5 \mathrm{~mL})$. The crude product was purified by flash chromatography on silica (hexane: $\mathrm{CH}_{2} \mathrm{Cl}_{2} \mathrm{1}: 2$ ) to give first BEDT-TTF and then compound 7 as an orange-yellow solid ( 0.75 g, 66\%), m.p. 185$187^{\circ} \mathrm{C} . \delta_{\mathrm{H}}\left(300 \mathrm{MHz}, \mathrm{CDCl}_{3}\right): 5.24(1 \mathrm{H}, \mathrm{m}, 2-H), 3.31\left(4 \mathrm{H}, \mathrm{s}, 5^{\prime}-\right.$ , $\left.6^{\prime}-H_{2}\right), 2.96\left(2 \mathrm{H}, \mathrm{dd}, J=13.7,2.1 \mathrm{~Hz}, 1-, 3-H_{\alpha}\right), 2.65(2 \mathrm{H}, \mathrm{dd}, J=$ 13.7, $\left.9.9 \mathrm{~Hz}, 1-, 3-H_{\beta}\right), 2.11(3 \mathrm{H}, \mathrm{s}, \mathrm{CH}) ; \delta_{\mathrm{C}}\left(75 \mathrm{MHz} \mathrm{CDCl}_{3}\right)$ : $169.48(\mathrm{C}=\mathrm{O}), 130.32,113.79,113.29 \& 111.66\left(6 \times \mathrm{sp}^{2} C\right), 77.22$ (2-C), $36.04(1-, 3-C), 30.16\left(-\mathrm{CH}_{2} \mathrm{CH}_{2}-\right), 21.06\left(\mathrm{CH}_{3}\right)$; IR $\nu_{\max }$ $\left(\mathrm{cm}^{-1}, \mathrm{KBr}\right): 2964$ (w), 2920 (w), 1740 (s), 1417 (w), 1292 (w), 1230 (vs), $1109(\mathrm{w}), 1014(\mathrm{~m}), 957(\mathrm{w}), 889(\mathrm{w}), 771(\mathrm{w}), 648(\mathrm{w}), 505$ (w); $m / z:\left(\mathrm{EI}^{+}\right) 456\left([\mathrm{M}]^{+}, 50 \%\right)$; HRMS: (EI) found $[\mathrm{M}]^{+} 455.85995$, $\mathrm{C}_{13} \mathrm{H}_{12} \mathrm{O}_{2} \mathrm{~S}_{8}$ requires 455.86031 . Further elution afforded the homo coupled cis and trans isomers of bis(2-acetoxypropylene1,3-dithio) tetrathiafulvalene 8 as an orange solid (70 $\mathrm{mg}$, 5\%), m.p. $270-273{ }^{\circ} \mathrm{C}(\mathrm{dec}) ; \delta_{\mathrm{H}}:\left(300 \mathrm{MHz}, \mathrm{CDCl}_{3}\right): 5.22(\mathrm{~m}, 2 \mathrm{H}$, $\left.2-, 2^{\prime}-H\right), 2.94\left(4 \mathrm{H}, \mathrm{dd}, J=14.4,2.7 \mathrm{~Hz}, 1^{-}, 1^{\prime}-, 3-, 3^{\prime}-H_{\alpha}\right), 2.66(4 \mathrm{H}$, $\left.\mathrm{m}, 1-, 1^{\prime}-, 3-, 3^{\prime}-H_{\beta}\right), 2.11 \& 2.10\left(6 \mathrm{H}, 2 \times \mathrm{CH}_{3}\right) ; \delta_{\mathrm{C}}:(75 \mathrm{MHz}$, $\left.\mathrm{CDCl}_{3}\right): 169.60 \& 169.49(\mathrm{C}=\mathrm{O}, 2$ isomers $), 130.30 \& 112.42(6 \times$ $\left.\mathrm{sp}^{2} C\right), 79.91\left(2-, 2^{\prime}-C\right), 36.12$ \& $36.00\left(1^{-}, 1^{\prime}-, 3-, 3^{\prime}-C, 2\right.$ isomers), $21.11\left(2 \times \mathrm{CH}_{3}\right)$; IR $\nu_{\max }\left(\mathrm{cm}^{-1}, \mathrm{KBr}\right): 2968(\mathrm{w}), 2920(\mathrm{w}), 1740$ (vs), 1423 (w), 1403 (w), 1369 (m), 1232 (vs), 1111 (w), 1020 (s), $960(\mathrm{~m}), 903(\mathrm{~m}), 770(\mathrm{w}), 646(\mathrm{w}), 501(\mathrm{w}) ; \mathrm{m} / \mathrm{z}:\left(\mathrm{FAB}^{+}\right) 528\left([\mathrm{M}]^{+}\right.$, 
100\%); HRMS: (FAB) found $[\mathrm{M}]^{+} 527.88348, \mathrm{C}_{16} \mathrm{H}_{16} \mathrm{O}_{4} \mathrm{~S}_{8}$ requires 527.88144 .

\section{Synthesis of (ethylenedithio)(2-hydroxypropylene-1,3 dithio) tetrathiafulvalene (H1)}

A solution of protected donor 7 (0.55 g, $1.21 \mathrm{mmol})$ in THF (30 $\mathrm{mL}$ ) and $6 \mathrm{M} \mathrm{HCl}$ solution $(6.5 \mathrm{~mL})$ was stirred under nitrogen for $40 \mathrm{~h}$. The solution was neutralized by the addition of solid $\mathrm{NaHCO}_{3}$. The organic layer was collected, washed with brine and dried over $\mathrm{MgSO}_{4}$. Removal of solvent yielded $\mathbf{H 1}$ as an orange-yellow solid (0.48 g, 96\%), m.p. $227-230{ }^{\circ} \mathrm{C}(\mathrm{dec}) . \delta_{\mathrm{H}}(600$ MHz, DMSO-d $\left.{ }_{6}\right): 5.62(1 \mathrm{H}, \mathrm{d}, J=3.6 \mathrm{~Hz}, \mathrm{OH}), 3.96(1 \mathrm{H}, \mathrm{m}, 2-H)$, $3.41\left(4 \mathrm{H}, \mathrm{s}, 5^{\prime}-, 6^{\prime}-H_{2}\right), 2.96\left(2 \mathrm{H}, \mathrm{dd}, J=14.4,2.4 \mathrm{~Hz}, 1-, 3-H_{\alpha}\right), 2.46$ $\left(2 \mathrm{H}, \mathrm{dd}, J=13.2,9.6 \mathrm{~Hz}, 1-, 3-H_{\beta}\right) ; \delta_{\mathrm{C}}\left(150 \mathrm{MHz}, \mathrm{DMSO}-\mathrm{d}_{6}\right)$ : 129.88, 113.26, 109.18 (6 × sp $\left.{ }^{2}-C\right), 73.50$ (2-C), $38.58(1-, 3-\mathrm{C})$, $29.99\left(-\mathrm{CH}_{2} \mathrm{CH}_{2}-\right)$; IR $\nu_{\max }\left(\mathrm{cm}^{-1}, \mathrm{KBr}\right): 3547(\mathrm{~s}), 3392(\mathrm{w}), 3313$ (w), $2958(\mathrm{w}), 2910(\mathrm{w}), 1728(\mathrm{w}), 1645(\mathrm{w}), 1551(\mathrm{w}), 1412(\mathrm{~m})$, $1290(\mathrm{w}), 1165(\mathrm{~m}), 1057(\mathrm{w}), 1013$ (vs), $918(\mathrm{w}), 889(\mathrm{~m}), 770(\mathrm{~m})$, $743(\mathrm{~m}), 507(\mathrm{w}), 463(\mathrm{w}) . \mathrm{m} / \mathrm{z}:\left(\mathrm{EI}^{+}\right) 414$ ([M] $\left.]^{+}, 100 \%\right)$; HRMS: (EI) found $[\mathrm{M}]^{+}$413.85016, $\mathrm{C}_{11} \mathrm{H}_{10} \mathrm{OS}_{8}$ requires 413.84975. Elem. anal. found $\mathrm{C}: 31.76, \mathrm{H}: 2.50 \% . \mathrm{C}_{11} \mathrm{H}_{10} \mathrm{OS}_{8}$ requires $\mathrm{C}: 31.88, \mathrm{H}$ : $2.43 \%$.

\section{Synthesis of (cis-4" $4^{\prime \prime}$-bis(acetoxymethyl)cyclopenta-1,2- dithio) (ethylene-dithio)tetrathiafulvalene (13)}

A suspension of oxo compound $12(1.72 \mathrm{~g}, 4.40 \mathrm{mmol})$ and unsubstituted thione $6(1.98 \mathrm{~g}, 8.80 \mathrm{mmol})$ in dry triethyl phosphite $(6 \mathrm{~mL})$ was heated to $90{ }^{\circ} \mathrm{C}$ under nitrogen for $16 \mathrm{~h}$. The mixture was cooled to RT and hexane $(40 \mathrm{~mL})$ was added to facilitate further precipitation. The solid was collected by filtration and washed with hexane $(5 \mathrm{~mL})$. The residue obtained was purified by a flash chromatography on silica eluting with $\mathrm{CH}_{2} \mathrm{Cl}_{2}$ to give 13 as an orange crystalline solid (1.31 g, 53\%), m.p. $168-170{ }^{\circ} \mathrm{C} . \delta_{\mathrm{H}}\left(300 \mathrm{MHz}, \mathrm{CDCl}_{3}\right): 4.06(2 \mathrm{H}, \mathrm{s}), \& 3.97(2 \mathrm{H}$, s) $\left(2 \times 4^{\prime \prime}-\mathrm{CH}_{2} \mathrm{O}\right), 3.92\left(2 \mathrm{H}, \mathrm{m}, 1^{\prime \prime}-2^{\prime \prime}-\mathrm{H}\right), 3.33\left(4 \mathrm{H}, \mathrm{s}, 5^{\prime}-, 6^{\prime}-H_{2}\right)$, $2.15\left(2 \mathrm{H}, \mathrm{m}, 3^{\prime \prime}-, 5^{\prime \prime}-H_{\alpha}\right), 2.10(3 \mathrm{H}, \mathrm{s}) \& 2.09(3 \mathrm{H}, \mathrm{s})\left(2 \times \mathrm{CH}_{3}\right), 1.86$ $\left(2 \mathrm{H}, \mathrm{m}, 3^{\prime \prime}-, 5^{\prime \prime}-H_{\beta}\right) ; \delta_{\mathrm{C}}\left(75 \mathrm{MHz}, \mathrm{CDCl}_{3}\right): 171.01(2 \times C=\mathrm{O})$, $124.51,113.78,112.56 \& 112.13\left(6 \times \mathrm{sp}^{2} C\right), 67.40 \& 65.88\left(2 \times 4^{\prime \prime}-\right.$ $\left.\mathrm{CH}_{2} \mathrm{O}\right), 52.31\left(1^{\prime \prime}-, 2^{\prime \prime}-C\right), 46.18\left(4^{\prime \prime}-C\right), 38.43\left(3^{\prime \prime}-, 5^{\prime \prime}-C\right), 30.15\left(5^{\prime}-\right.$ , $\left.6^{\prime}-\mathrm{H}_{2}\right), 20.81\left(2 \times \mathrm{CH}_{3}\right)$; IR $\nu_{\max }\left(\mathrm{cm}^{-1}, \mathrm{KBr}\right): 2947(\mathrm{w}), 2924(\mathrm{w})$, 2854 (w), 1732 (vs), 1433 (w), 1367 (m), 1236 (vs), 1038 (s), 987 (w), $912(\mathrm{w}), 889(\mathrm{w}), 768(\mathrm{w}), 679(\mathrm{w}), 606(\mathrm{w}), 449(\mathrm{w}) ; \mathrm{m} / \mathrm{z}$ : (FAB) $568\left([\mathrm{M}]^{+}, 100 \%\right)$; HRMS: (FAB) found $[\mathrm{M}]^{+}$567.91530, $\mathrm{C}_{19} \mathrm{H}_{20} \mathrm{O}_{4} \mathrm{~S}_{8}$ requires 567.91274.

\section{Synthesis of (cis-4" $4^{\prime \prime}$-bis(hydroxymethyl)cyclopenta-1,2- dithio) (ethylene-dithio)tetrathiafulvalene (H2)}

A solution of the bis(acetyl) protected donor 13 (1.17 g, 2.06 $\mathrm{mmol})$ in THF (50 mL) and $6 \mathrm{M} \mathrm{HCl}$ solution $(22 \mathrm{~mL})$ was stirred under $\mathrm{N}_{2}$ for $43 \mathrm{~h}$. THF $(80 \mathrm{~mL})$ was added and the mixture was neutralized by the addition of solid $\mathrm{NaHCO}_{3}$. The organic layer was collected and dried over $\mathrm{MgSO}_{4}$. The crude product was purified by chromatography on silica firstly eluted with THF : hexane $(3: 2)$ to remove side products, followed by THF to elute H2. Further product was obtained by thorough extraction of silica from the top of the column with THF, evaporation and washing the solid with $\mathrm{CH}_{2} \mathrm{Cl}_{2}$. $\mathbf{H} 2$ was obtained as a yellow solid (0.65 g, 65\%), m.p. $211-213{ }^{\circ} \mathrm{C}(\mathrm{dec}) . \delta_{\mathrm{H}}(600 \mathrm{MHz}$, DMSO$\left.\mathrm{d}_{6}\right): 4.67(\mathrm{~s}, 2 \mathrm{H}, 2 \times \mathrm{OH}), 4.01\left(2 \mathrm{H}, \mathrm{m}, 2 \times 1^{\prime \prime}, 2^{\prime \prime}-H\right), 3.41(4 \mathrm{H}, \mathrm{s}$, $\left.5^{\prime}-, 6^{\prime}-\mathrm{H}_{2}\right), 3.28(2 \mathrm{H}, \mathrm{s}) \& 3.25(2 \mathrm{H}, \mathrm{s})\left(2 \times 4^{\prime \prime}-\mathrm{CH}_{2} \mathrm{O}\right), 1.95(2 \mathrm{H}, \mathrm{m}$, $\left.3^{\prime \prime}-, 5^{\prime \prime}-H_{\alpha}\right), 1.61\left(2 \mathrm{H}, \mathrm{m}, 3^{\prime \prime}-, 5^{\prime \prime}-H_{\beta}\right) ; \delta_{\mathrm{C}}(150 \mathrm{MHz}): 123.01,113.22$, $111.70 \& 111.38\left(6 \times \mathrm{sp}^{2} C\right), 65.90 \& 64.52\left(2 \times 4^{\prime \prime}-\mathrm{CH}_{2} \mathrm{O}\right), 52.14$ $\left(1^{\prime \prime}-, 2^{\prime \prime}-C\right), 49.87\left(4^{\prime \prime}-C\right), 37.74\left(3^{\prime \prime}-, 5^{\prime \prime}-C\right), 29.95\left(5^{\prime}-, 6^{\prime}-H_{2}\right)$; IR $\nu_{\max }$ $\left(\mathrm{cm}^{-1}, \mathrm{KBr}\right): 3305$ (vs, br), $2918(\mathrm{~m}), 2868(\mathrm{~m}), 1645(\mathrm{w}), 1551(\mathrm{w})$, 1439 (m), 1406 (m), 1284 (m), 1255 (w), 1198 (m), 1146 (w), 1088 (w), 1041 (vs), 1018 (vs), 908 (m), 771 (m), 679 (w), 577 (w), 473 (w); $m / z:(\mathrm{FAB}) 484\left([\mathrm{M}]^{+}, 60 \%\right) ; m / z:\left(\mathrm{EI}^{+}\right) 484\left([\mathrm{M}]^{+}, 10 \%\right)$; HRMS: (EI) found $[\mathrm{M}]^{+} 483.89134, \mathrm{C}_{15} \mathrm{H}_{16} \mathrm{O}_{2} \mathrm{~S}_{8}$ requires 483.89161; elem. anal. found C: $36.38, \mathrm{H}: 3.13 \% ; \mathrm{C}_{15} \mathrm{H}_{16} \mathrm{O}_{2} \mathrm{~S}_{8^{-}}$ $\cdot 0.25 \mathrm{CH}_{2} \mathrm{Cl}_{2}$ requires C: $36.22, \mathrm{H}: 3.27 \%$.

\section{$( \pm)\left(1^{\prime \prime} R, 5 R\right)$ - and $\left(1^{\prime \prime} R, 5 S\right)\left(1^{\prime \prime}\right.$-acetoxybutyl)bis-} (ethylenedithio)tetrathiafulvalene (17)

A suspension of oxo compound $16(1.54 \mathrm{~g}, 4.78 \mathrm{mmol})$ and unsubstituted thione $6(2.13 \mathrm{~g}, 9.56 \mathrm{mmol})$ in dry triethyl phosphite $(7 \mathrm{~mL})$ was heated to $90{ }^{\circ} \mathrm{C}$ under nitrogen for $24 \mathrm{~h}$. The mixture was cooled to RT and triethyl phosphite was removed by distillation under reduced pressure. The residue was purified by flash chromatography on silica (hexane : DCM $1: 1)$ to give 17 as an orange solid (1.34 g, 56\%). ${ }^{1} \mathrm{H}$ NMR showed the product was a mixture of diastereomers with estimated ratio $65: 35$. m.p. $78-80{ }^{\circ} \mathrm{C} ; \delta_{\mathrm{H}}\left(300 \mathrm{MHz}, \mathrm{CDCl}_{3}\right): 5.20$ $\left(0.35 \mathrm{H}, \mathrm{q}, J=6.1 \mathrm{~Hz}, 1^{\prime \prime}-H\right), 5.15\left(0.65 \mathrm{H}, \mathrm{q}, J=6.1 \mathrm{~Hz}, 1^{\prime \prime}-H\right), 3.79$ $(1 \mathrm{H}, \mathrm{m}, 5-H), 3.31\left(4 \mathrm{H}, \mathrm{s}, 5^{\prime}-6^{\prime}-H_{2}\right), 3.20\left(1 \mathrm{H}, \mathrm{m}, 6-H_{\alpha}\right), 3.08(1 \mathrm{H}$, $\left.\mathrm{m}, 6-H_{\beta}\right), 2.11\left(3 \mathrm{H}, \mathrm{s}, \mathrm{CH}_{3} \mathrm{CO}\right), 1.73\left(2 \mathrm{H}, \mathrm{m}, 2^{\prime \prime}-H_{2}\right), 1.37(2 \mathrm{H}, \mathrm{m}$, $\left.3^{\prime \prime}-\mathrm{H}_{2}\right), 0.96\left(3 \mathrm{H}, \mathrm{t}, J=7.3 \mathrm{~Hz}, 4^{\prime \prime}-H_{3}\right) ; \delta_{\mathrm{C}}(75 \mathrm{MHz}): 170.34 \&$ $170.18(C=\mathrm{O}), 115.60,115.22,114.99 \& 113.84\left(6 \times \mathrm{sp}^{2} C\right), 73.68$ \& $73.63\left(1^{\prime \prime}-C\right), 49.49 \& 48.78(5-C), 33.89 \& 33.81\left(2^{\prime \prime}-C\right), 32.95 \&$ $32.22(6-C), 30.20\left(5^{\prime}-, 6^{\prime}-C\right), 20.94\left(\mathrm{CH}_{3} \mathrm{CO}\right), 18.57 \& 18.36\left(3^{\prime \prime}-C\right)$, $13.84 \& 13.79\left(4^{\prime \prime}-C\right)$; IR $\nu_{\max }\left(\mathrm{cm}^{-1}, \mathrm{KBr}\right): 2954(\mathrm{w}), 2922(\mathrm{w})$, 2866 (w), 1738 (s), 1458 (w), 1410 (w), 1367 (m), 1227 (vs), 1120 (w), $1020(\mathrm{~m}), 887(\mathrm{w}), 770(\mathrm{~m}), 635(\mathrm{w}), 606(\mathrm{w}), 490(\mathrm{w}) ; \mathrm{m} / \mathrm{z}$ : $\left(\mathrm{FAB}^{+}\right) 498\left([\mathrm{M}]^{+}, 100 \%\right)$; HRMS: (FAB) found $[\mathrm{M}]^{+}$497.90754, $\mathrm{C}_{16} \mathrm{H}_{18} \mathrm{O}_{2} \mathrm{~S}_{8}$ requires 497.90726 .

\section{Synthesis of $( \pm)\left(1^{\prime \prime} R, 5 R\right)$ - and $\left(1^{\prime \prime} R, 5 S\right)-\left(1^{\prime \prime}\right.$-hydroxybutyl) bis(ethylenedithio)tetrathiafulvalene (H3)}

A solution of ester $17(1.30 \mathrm{~g}, 2.61 \mathrm{mmol})$ in THF (30 mL) and 6 $\mathrm{M} \mathrm{HCl}$ solution (16 mL) was stirred under nitrogen for $40 \mathrm{~h}$. The solution was neutralized by the addition of solid $\mathrm{NaHCO}_{3}$. The organic layer was collected, washed with brine and dried over $\mathrm{MgSO}_{4}$. Removal of solvent yielded a sticky residue, which was purified by flash chromatography on silica (hexane : $\mathrm{CH}_{2} \mathrm{Cl}_{2}$ $1: 1)$ to afford a sticky orange solid. Recrystallisation from $\mathrm{CH}_{2} \mathrm{Cl}_{2} /$ hexane gave $\mathbf{H 3}$ as an orange solid (0.77 g, 65\%), m.p. 101-103 ${ }^{\circ} \mathrm{C}$; ${ }^{1} \mathrm{H}$ NMR showed the product was a mixture of diastereomers with estimated ratio $4: 1 . \delta_{\mathrm{H}}\left(300 \mathrm{MHz}, \mathrm{CDCl}_{3}\right)$ : $3.85\left(1 \mathrm{H}, \mathrm{m}, 1^{\prime \prime}-\mathrm{H}\right), 3.67(0.2 \mathrm{H}, \mathrm{m}, 5-H), 3.54(0.8 \mathrm{H}, \mathrm{m}, 5-H), 3.29$ $\left(4 \mathrm{H}, \mathrm{m}, 5^{\prime}-, 6^{\prime}-H_{2}\right), 2.11(0.2 \mathrm{H}, \mathrm{d}, J=5.4 \mathrm{~Hz}, \mathrm{OH}), 2.00(0.8 \mathrm{H}, \mathrm{d}, J$ $=3.6 \mathrm{~Hz}, \mathrm{OH}), 1.58\left(4 \mathrm{H}, \mathrm{m}, 2^{\prime \prime}-3^{\prime \prime}-H_{2}\right), 0.95\left(3 \mathrm{H}, \mathrm{t}, J=7.0 \mathrm{~Hz}, 4^{\prime}-\right.$ $\left.H_{3}\right) ; \delta_{\mathrm{C}}\left(75 \mathrm{MHz}, \mathrm{CDCl}_{3}\right): 115.05,114.35,113.87,111.89(6 \times$ $\left.\mathrm{sp}^{2} C\right), 72.41 \& 72.25\left(1^{\prime \prime}-C\right), 52.77 \& 50.25(5-C), 36.76 \& 36.56\left(2^{\prime \prime}-\right.$ 
$C), 33.18 \& 31.54(6-C), 30.20\left(5^{\prime}-, 6^{\prime}-C\right), 18.92 \& 18.83\left(3^{\prime \prime}-C\right), 13.97$ \& $13.95\left(4^{\prime \prime}-C\right)$; IR $\nu_{\max }\left(\mathrm{cm}^{-1}, \mathrm{KBr}\right): 3402$ (br), 3334 (br, sh), 2951 (s), 2918 (s), $2864(\mathrm{~m}), 1655$ (w), $1514(\mathrm{w}), 1456(\mathrm{w}), 1408(\mathrm{~m})$, 1282 (m), 1223 (w), 1115 (m), 1066 (m), 1020 (m), 1003 (m), 908 (s), $847(\mathrm{w}), 770(\mathrm{~s}), 592(\mathrm{w}), 503(\mathrm{w}), 449(\mathrm{w}) ; \mathrm{m} / \mathrm{z}$ : (FAB) 456 $\left([\mathrm{M}]^{+}, 100 \%\right)$; elem. anal. found C: $36.89, \mathrm{H}: 3.54 \% ; \mathrm{C}_{14} \mathrm{H}_{16} \mathrm{OS}_{8}$ requires $\mathrm{C}: 36.84, \mathrm{H}: 3.51 \%$.

\section{Preparation of $\left[(\mathrm{H} 1) \mathrm{I}_{3}\right] \cdot 0.5 \mathbf{I}_{2}(18)$}

A solution of donor $\mathbf{H 1}(12 \mathrm{mg})$ in $\mathrm{CH}_{2} \mathrm{Cl}_{2}(3 \mathrm{~mL})$ was gently added to a solution of iodine $(8 \mathrm{mg})$ in $\mathrm{CH}_{2} \mathrm{Cl}_{2}(3 \mathrm{~mL})$. Slow evaporation in the dark afforded a few black crystals after one week, m.p. $195{ }^{\circ} \mathrm{C}$ (dec); elem. anal. found C: 14.38 , H: $1.13 \%$; $\mathrm{C}_{11} \mathrm{H}_{10} \mathrm{I}_{4} \mathrm{OS}_{8}$ requires C: $14.32, \mathrm{H}: 1.09 \%$.

\section{Preparation of $\left[(\mathrm{HMET}) \mathbf{I}_{3}\right](19)$}

A solution of iodine $(20.1 \mathrm{mg})$ in acetonitrile $(8 \mathrm{~mL})$ was gently layered on top of a solution of HMET $(12.5 \mathrm{mg})$ in THF $(6 \mathrm{~mL})$ in a test tube and left to stand in the dark for 1 week affording black plate-like crystals, m.p. $190{ }^{\circ} \mathrm{C}(\mathrm{dec})$; IR $\nu_{\max }\left(\mathrm{cm}^{-1}, \mathrm{KBr}\right)$ : 3280 (w), 2911 (w), 2170 (w), 1592 (m), 1450 (s), 1397 (s), 1332 (s), $1281(\mathrm{~m}), 1141(\mathrm{~m}), 1118(\mathrm{~m}), 1047(\mathrm{~m}), 996(\mathrm{~s}), 889(\mathrm{~s}), 766(\mathrm{~m})$, 743 (w); HRMS: (EI) found $[\mathrm{M}]^{+} 413.8488, \mathrm{C}_{11} \mathrm{H}_{10} \mathrm{OS}_{8}$ requires 413.8492; elem. anal. found $\mathrm{C}: 16.95, \mathrm{H}: 1.29 ; \mathrm{C}_{11} \mathrm{H}_{10} \mathrm{I}_{3} \mathrm{OS}_{8}$ requires $\mathrm{C}: 17.20, \mathrm{H} 1.23 \%$.

\section{X-ray structure determination}

Single crystals of $\mathbf{H 1}, \mathbf{H 2}, \mathbf{1 3}$, and the radical cation salt 18 were mounted on a cryoloop with paratone oil and examined on a Bruker APEX-II CCD diffractometer equipped with an Oxford Cryoflex low temperature device. Data were measured at 150(2) K using graphite-monochromated $\mathrm{Mo}-\mathrm{K}_{\alpha}$ radiation $(\lambda=0.71073 \AA)$ and the APEX-II software. ${ }^{\mathbf{1 6}}$ Final cell constants were determined from full least squares refinement of all observed reflections. The data were corrected for absorption SADABS. ${ }^{17}$ Cell refinement and data-reduction were carried out by SAINT. ${ }^{16}$ For 19 , the $\mathrm{X}$-ray data was collected on single crystals at $150 \mathrm{~K}$ on an Agilent Xcalibur diffractometer equipped with a Sapphire detector and an Oxford Cryosystems Cryocool low temperature device using the CrysAlis-Pro software package. ${ }^{18 a}$ With the exception of 13 and 19, the structures were solved by direct methods (SHELXS97) and refined with full least squares refinement on $F^{2}$ using SHELXL-97 within the Bruker SHELXTL suite. ${ }^{18 b}$ One of the six membered rings in $\mathbf{H 1}$ is disordered and was modelled over two sites. Discorded solvent was removed from the final model of $\mathbf{H 1}$ using PLATON SQUEEZE. ${ }^{19}$ Compounds 13 and 19 were solved with direct methods (SHELXS-97) and refined using SHELXL2013. ${ }^{18 a}$ The structure of $\mathbf{1 3}$ exhibited disorder of cyclopentane ring that was modelled over two sites. Initial structure solution of 19 revealed 1.5 BEDT fragments in the asymmetric unit and one well-ordered $\mathrm{I}_{3}{ }^{-}$anion. However the second $\mathrm{I}_{3}{ }^{-}$ion was severely disordered over multiple sites about a special position. A total of 9 positions were modelled with a total site occupancy of 1.5 which brought the residual electron density within $1.5 \mathrm{e}^{-}$ $\AA^{-3}$. Attempts to clearly identify the $\mathrm{CH}_{2} \mathrm{OH}$ group positions on each BEDT core were unsuccessful although some low intensity peaks in the difference map were evident suggestive of severe disorder in the positions of the $\mathrm{CH}_{2} \mathrm{OH}$ units. The unsaturated nature of the backbone afforded 8 possible positions for the $\mathrm{CH}_{2} \mathrm{OH}$ group (and four for the $\mathrm{CH}_{2} \mathrm{OH}$ group attached to the BEDT molecule located about a special position). With a shortage of well-defined potential positions in the difference map, $\mathrm{CH}_{2} \mathrm{OH}$ side-chains were added using a FRAG $\cdots$ FEND command. Their positions were subsequently refined using appropriate 1,2- and 1,3-distance restraints (DFIX) and their site occupancies refined using a common thermal parameter (EADP). For the BEDT fragment on a general position four $\mathrm{CH}_{2} \mathrm{OH}$ positions were modelled, one on each of the crystallographically independent unsaturated $\mathrm{C}$ atoms of the BEDT backbone to afford a total site occupancy of 1.0 (SUMP). For the BEDT molecule located about a special position an additional two $\mathrm{CH}_{2} \mathrm{OH}$ groups were modelled with a total site occupancy of 0.5 (SUMP). Notwithstanding these efforts the $U_{\text {iso }}$ for both the $\mathrm{C}$ and $\mathrm{O}$ atoms of the $\mathrm{CH}_{2} \mathrm{OH}$ groups were abnormally large indicating that the disorder was even more severe than the current model indicates. Attempts to model the disorder over even more sites was not considered. Crystallographic parameters for H1, H3, 13, 18 and 19 are summarized in Table $1 . \dagger$

\section{Computational studies}

DFT calculations were carried out on $\mathbf{H 1}$ and $\mathbf{H} 2$ with initial geometry optimizations undertaken using the Pople 6-31G*+ basis set and B3LYP functional within Jaguar. ${ }^{20}$ Subsequent single-point energy calculations were performed on the optimized structure using the larger triple zeta 6-311G-3DF-3PD basis set. ${ }^{21}$

\section{Thin film preparation}

Polystyrene film comprising (H3) $)_{x}$ (polyiodides) $)_{y}$ on a $\mathrm{Si}$ wafer. $^{22,23}$ A polymer blend thin-film containing 1:1 weight ratio of donor/PS on a Si wafer substrate was prepared by spin coating a 2 wt $\%$ solution of donor/PS (1:1 weight ratio) in chlorobenzene at $1000 \mathrm{rpm}$ for $45 \mathrm{~s}$. The film was dried in a vacuum oven at $65{ }^{\circ} \mathrm{C}$ for $3 \mathrm{~h}$ to remove any solvent residue and then $\mathrm{Au}$ electrodes were deposited onto the film via vacuum deposition through a shadow mask. The film was then doped with iodine vapour by suspending the film above an $\mathrm{I}_{2} / \mathrm{CH}_{2} \mathrm{Cl}_{2}$ $(100 \mathrm{mg} / 20 \mathrm{~mL})$ solution for $8 \mathrm{~min}$ at RT.

Polystyrene film comprising (H3) ${ }_{x}$-(polyiodides) $)_{y}$ on a glass substrate. $^{24,25}$ A non-conductive polystyrene film (MW 45 000) (20 $\mu \mathrm{m}$ thickness) on a glass substrate containing a $2 \mathrm{wt} \%$ of molecularly dispersed donor in a polystyrene matrix were obtained by casting from a solution of PS polymer and BEDTTTF derivative in $o$-dichlorobenezene at $120{ }^{\circ} \mathrm{C}$. The film was then exposed to iodine vapour by suspending the film over an $\mathrm{I}_{2} /$ $\mathrm{CH}_{2} \mathrm{Cl}_{2}$ solution $(0.1 \mathrm{~g} / 20 \mathrm{~mL})$ for $8 \mathrm{~min}$. Such treatment resulted in the formation of a continuous network containing $(\mathbf{H} 3)_{x}$-(polyiodides) $)_{y}$ in a surface layer of the polystyrene film.

Device fabrication and evaluation. The fabrication of the device was accomplished at ambient conditions without taking any precautions to isolate the material and device from exposure to ambient oxygen, moisture, or light. Experimental 
Table 1 X-ray crystallographic parameters

\begin{tabular}{|c|c|c|c|c|c|}
\hline Complex & H1 & H2 & 13 & 18 & 19 \\
\hline Formula & $\mathrm{C}_{11} \mathrm{H}_{10} \mathrm{OS}_{8}$ & $\mathrm{C}_{16} \mathrm{H}_{16} \mathrm{O}_{4} \mathrm{~S}_{8}$ & $\mathrm{C}_{19} \mathrm{H}_{20} \mathrm{O}_{4} \mathrm{~S}_{8}$ & $\mathrm{C}_{22} \mathrm{H}_{2} \mathrm{OI}_{6.6} \mathrm{O}_{2} \mathrm{~S}_{16}$ & $\mathrm{C}_{11} \mathrm{H}_{10} \mathrm{OS}_{8} \mathrm{I}_{3}$ \\
\hline Formula mass & 414.67 & 528.77 & 568.83 & 1666.37 & 795.37 \\
\hline Crystal size/mm & $0.32 \times 0.10 \times 0.08$ & $0.60 \times 0.50 \times 0.40$ & $0.30 \times 0.23 \times 0.05$ & $0.3 \times 0.1 \times 0.01$ & $0.26 \times 0.20 \times 0.04$ \\
\hline Description & Plate & Block & Plate & Plate & Plate \\
\hline Crystal colour & Orange & Orange & Orange & Black & Black \\
\hline$b / \AA$ & $15.314(2)$ & $11.4272(8)$ & $12.1870(7)$ & $8.6449(4)$ & $13.7315(7)$ \\
\hline$c / \AA$ & $16.664(2)$ & $12.9575(9)$ & $15.5413(9)$ & $16.2901(8)$ & $33.707(3)$ \\
\hline$\alpha /^{\circ}$ & $89.607(7)$ & 90 & $111.004(3)$ & $87.891(2)$ & 90 \\
\hline$\beta /^{\circ}$ & $89.350(8)$ & $95.606(3)$ & $100.434(3)$ & $86.545(2)$ & $98.022(6)$ \\
\hline$\gamma /{ }^{\circ}$ & $88.861(7)$ & 90 & $91.420(3)$ & $76.982(2)$ & 90 \\
\hline$V\left(\AA^{3}\right)$ & $1677.8(4)$ & 2101.6(3) & $1138.86(11)$ & 1085.02(9) & $6672.9(8)$ \\
\hline$R_{\text {int }}$ & 0.073 & 0.025 & 0.063 & 0.0696 & 0.0608 \\
\hline$R_{1}(I>2 \sigma(I))$ & 0.043 & 0.032 & 0.029 & 0.0696 & 0.0893 \\
\hline $\mathrm{w} R_{2}$ (all data) & 0.116 & 0.079 & 0.078 & 0.1872 & 0.2140 \\
\hline Goof & 1.06 & 1.09 & 1.04 & 1.05 & 1.115 \\
\hline Number of parameters & 386 & 255 & 301 & 232 & 313 \\
\hline$\Delta \rho_{\max } \Delta \rho_{\min }\left(\mathrm{e} \AA^{-3}\right)$ & $+0.71,-0.64$ & $+1.12,-0.45$ & $+0.58,-0.35$ & $+3.96,-2.56$ & $+1.29,-1.24$ \\
\hline
\end{tabular}

bottom-gate thin film transistor (TFT) devices were built onto an $n$-doped silicon wafer as the gate electrode with a $100 \mathrm{~nm}$ thermal $\mathrm{SiO}_{2}$ as the dielectric layer, with or without an octyltrichlorosilane (OTS) modified monolayer. The performances were measured in a top-contact configuration (drain and source electrodes deposited above the semiconductor). Gold source and drain contacts were deposited onto the organic layer through a shadow mask. The device characteristics were measured in air at room temperature using a Keithley 4200 SCS semiconductor parameter analyser.

\section{Results and discussion}

\section{Synthesis}

Building on our previous studies, ${ }^{13,14}$ a family of four hydroxyl functionalized BEDT-TTF derivatives were prepared, comprising three new donors H1-H3 as well as the previously reported HMET 2. ${ }^{13 d} \mathbf{H} \mathbf{1}$ and $\mathbf{H} \mathbf{2}$ are achiral, HMET is a racemate and $\mathbf{H} 3$ was isolated as mixture of two diastereoisomers. It should be noted that for a side chain located on the sixmembered ring of a BEDT-TTF derivative, the conformation of the ring can adjust between half chairs so that the $R$ or $S$ configured side chain can be orientated into similar positions. The general synthetic strategy for the preparation of the donors involves preparation of fused 1,3-dithiole-2-thiones, protection of their hydroxyl groups as acetates followed by formation of the central carbon-carbon double bond via a phosphite-mediated coupling reaction of the thione or its corresponding oxo compound and subsequent deprotection of the hydroxyl group. Thus, for $\mathbf{H 1}$ which has terminal six- and seven-membered rings, the hydroxyl substituted seven-membered ring thione
3 was obtained by cyclisation of the zinc complex of 2-thioxo-1,3-dithiole-4,5-dithiolate, $\left(\mathrm{NEt}_{4}\right)_{2}\left[\mathrm{Zn}(\mathrm{dmit})_{2}\right]^{26,27}$ with 1,3-dibromopropan-2-ol, Scheme $1 .^{28}$ The hydroxyl group was protected as an acetate to give $\mathbf{4}$ which was converted to the corresponding oxo compound $\mathbf{5}$ by treatment with mercuric acetate. Reaction of 5 with the unsubstituted six-membered ring thione $6^{29}$ in triethyl phosphite afforded the cross-coupled acetyl-protected donor 7 in $66 \%$ yield, along with BEDT-TTF and a small amount of the homo-coupled bis-acetyl protected donor $8(5 \%)$ after chromatography. Deprotection of 7 with $\mathrm{HCl}$ in THF afforded $\mathbf{H 1}$ in an almost quantitative yield.

The bis(hydroxymethyl) donor $\mathbf{H 2}$ was prepared via the cycloaddition of 3,3-bis(hydroxymethyl)cyclopentene ${ }^{30}$ with trithione 9 to give thione 10 in $66 \%$ yield which was converted to

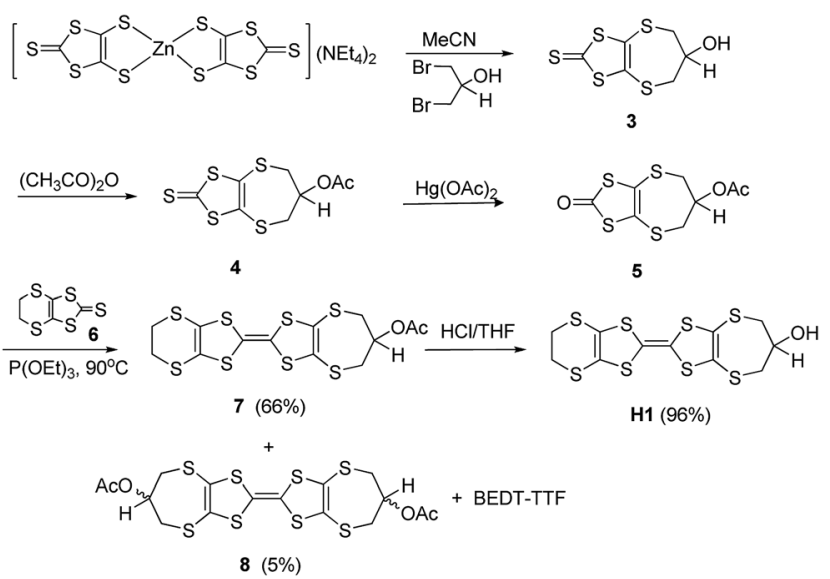

Scheme 1 

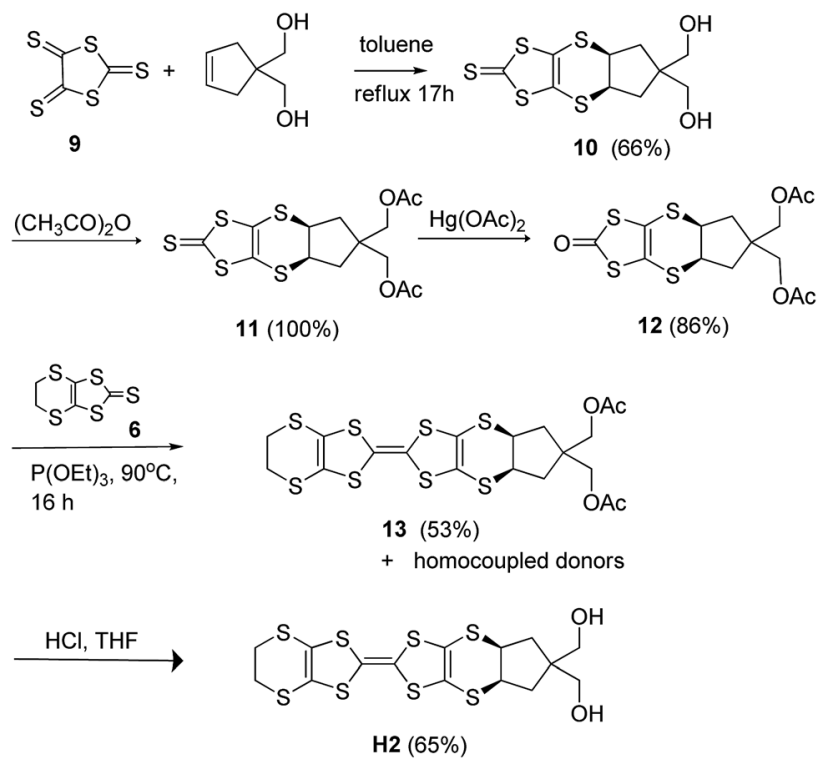

Scheme 2

the bis(acetate) 11 and then treated with $\mathrm{Hg}(\mathrm{OAc})_{2}$ to provide the oxo compound 12 in $86 \%$ yield.

Cross-coupling of 12 with the unsubstituted thione 6 afforded donor $\mathbf{1 3}$ in 53\% yield. Deprotection of $\mathbf{1 3}$ in acidic conditions afforded donor $\mathbf{H 2}$ as a yellow solid in $65 \%$ yield, scheme 2 .

Donor H3, a BEDT-TTF derivative bearing a 1-hydroxybutyl side chain, was prepared from trithione $\mathbf{9}^{29}$ via cycloaddition with hex-1-en-3-ol to give thione 14 as a $(65: 35)$ mixture of diastereomers in $71 \%$ yield. Protection of the hydroxyl group as acetate $\mathbf{1 5}$, conversion of this thione to the corresponding oxo derivative 16 and cross coupling with the unsubstituted thione 6 afforded the mono-substituted donor $\mathbf{1 7}$ in 56\% yield together with the homo coupled adducts. Deprotection of 17 with hydrochloric acid in THF afforded donor $\mathbf{H} 3$ as a mixture of diastereomers which could not be completely separated by chromatography or recrystallization, Scheme 3.

\section{X-ray crystallography}

Single crystals of $\mathbf{H 1}$ and $\mathbf{H} 2$ and the $O$-acetylated precursor 13 were characterized by X-ray diffraction to study the dominant molecular interactions in the crystal packing of the neutral donors. Given that the molecular structures of these compounds dictate their electrical properties, crystallographic studies are crucial to shed light on how synthetic modifications to the BEDT-TTF framework disrupts the tendency of the donors to stack in the solid state. Finally, in order for these materials to become electronic conductors they are typically doped with iodine. In order to investigate how the crystal structures of the donors are altered after oxidation to radical cations, donors H1 and HMET were doped with iodine and the structures of their radical cation salts were elucidated by X-ray diffraction. For all five structures, selected bond lengths and angles are reported in S- 2 of the ESI. $\dagger$

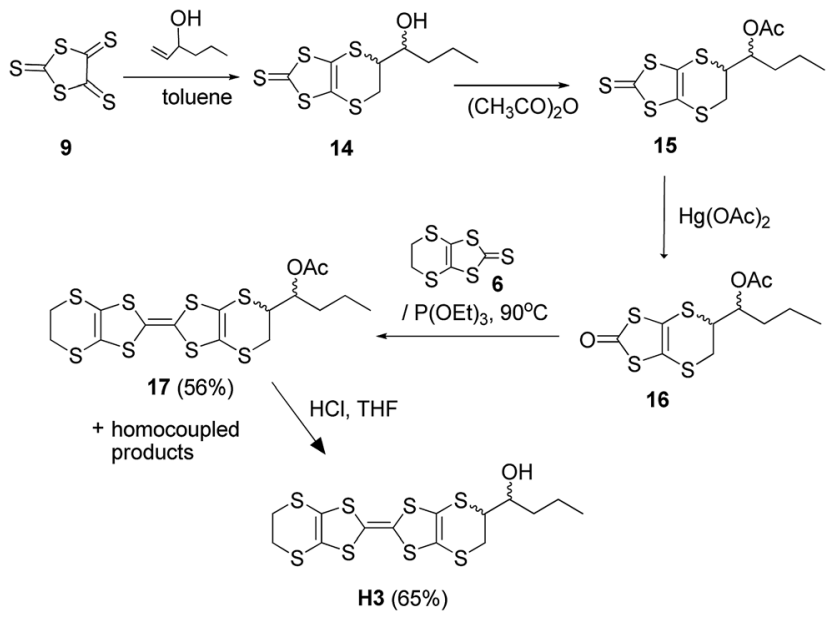

Scheme 3

\section{Hydroxyl donors $\mathrm{H} 1$ and $\mathrm{H} 2$}

Single crystals of $\mathbf{H} \mathbf{1}$ were obtained via diffusion of hexane into a THF solution of the donor. The compound crystallizes in the triclinic space group $P \overline{1}$ with two independent molecules, $\mathbf{A}$ and $\mathbf{B}$, in the asymmetric unit, Fig. 2.

Both donors are slightly bowed due to bends about their dithiole $S \cdots S$ vectors in the range $17.9-23.9^{\circ}$. The ethylene bridges in both molecules are disordered between two half chair conformations for molecule $\mathbf{A}$ and two envelope conformations for molecule $\mathbf{B}$, a feature which is common for such systems. ${ }^{13,14}$ The seven-membered rings of both molecules crystallize in chair conformations with the hydroxyl groups adopting pseudoaxial orientations. The molecules are packed as centrosymmetric pairs in a head-to-tail manner with neighbouring dimers situated almost at right angles to one another, Fig. 3.

Within each pair, the central TTF units are offset from one another along the molecular axis so there are two $\mathrm{S} \cdots \mathrm{S}$ contacts per dimer of 3.5067(8) and 3.6065(8) $\AA$, close to the $S \cdots S$ van der Waals distance of $3.6 \AA$. Donor pairs are assembled into layers in the $c a+b$ plane, such that the hydroxyl groups of four donors can hydrogen bond to each other forming a roughly square arrangement between the oxygen atoms $(\mathrm{O} \cdots \mathrm{O}: 2.673(2)$ and $2.727(2) \AA ̊)$, Fig. 3. This type of square shaped hydrogen bonded motif has also been observed previously for the triiodide salt of bis(2R-2,3-dihydroxypropylthio) (ethylenedithio)TTF. ${ }^{13 b}$ For H1 the hydrogen bonding between donors dominates the crystal packing, and there are no short $\mathrm{S} \cdots \mathrm{S}$ contacts between coparallel stacks of donors in the crystal lattice. In contrast,

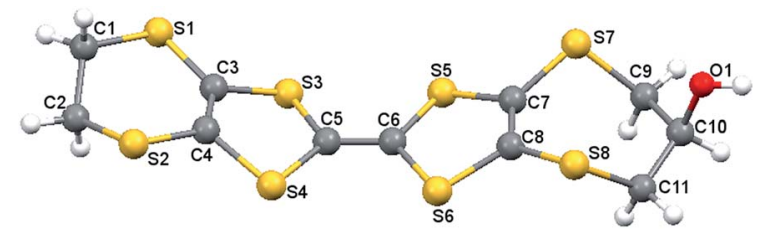

Fig. 2 Molecular structure of one independent molecule (B) of $\mathrm{H} 1$ with atomic labelling scheme. 


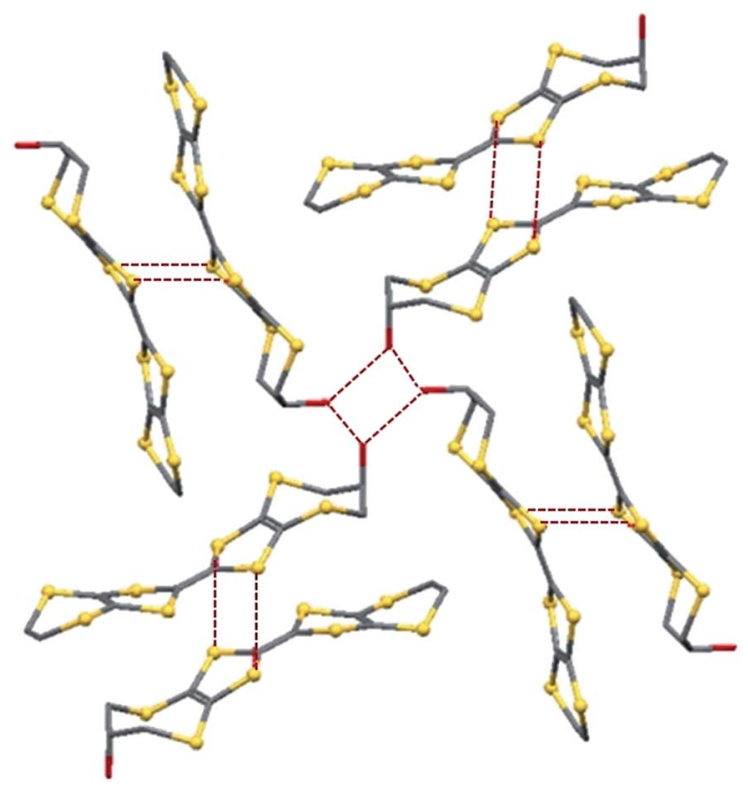

Fig. 3 Crystal packing arrangement of $\mathrm{H} 1$. View down the $a^{*}$-axis showing four dimers participating in a hydrogen bonded "square motif." S ...S contacts between pairs of dimers and H-bonding interactions between hydroxyl groups are shown as red dashed lines. $\mathrm{H}$ atoms are omitted for clarity.

there are several short edge-to-edge $S \cdots S$ contacts between donors in neighbouring layers of 3.4121(8) A and several longer interactions in the range $3.5067(8)-3.594(1) \AA$ that could mediate electronic communication between donor molecules, Fig. 4. Channels running through the structure contain disordered hexane molecules which were excluded from the final model using PLATON SQUEEZE. ${ }^{19}$

Single crystals of $\mathbf{H} 2$ were obtained by the diffusion of $\mathrm{Et}_{2} \mathrm{O}$ into a DMF solution of the donor. The molecule crystallizes in the monoclinic space group $P 2_{1} / c$. The framework of the donor is slightly bowed due to small bends of 12.9 and $13.4^{\circ}$ about the dithiole $\mathrm{S} \cdots \mathrm{S}$ vectors. The fused cyclopentane ring adopts a half chair conformation with the largest torsion about a $\mathrm{CH}-\mathrm{CH}_{2}$ bond, Fig. 5 .

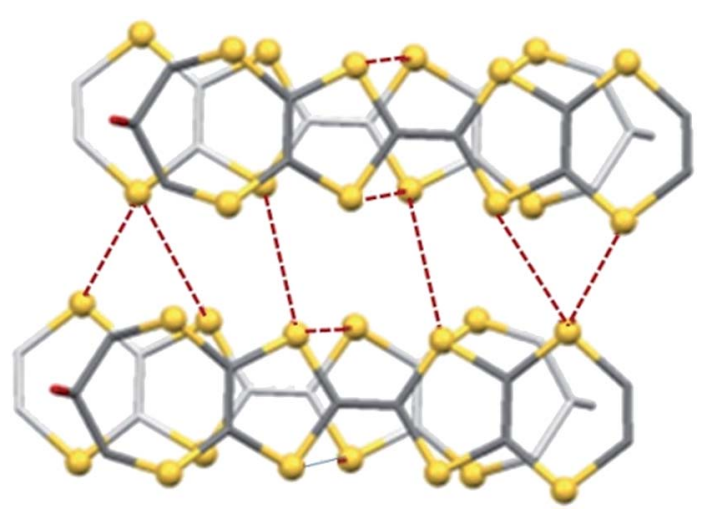

Fig. 4 Crystal packing arrangement of $\mathrm{H} 1$, showing $\mathrm{S}$... S contacts (red dashed lines) between molecules belonging to adjacent donor pairs. $\mathrm{H}$-atoms are omitted for clarity.

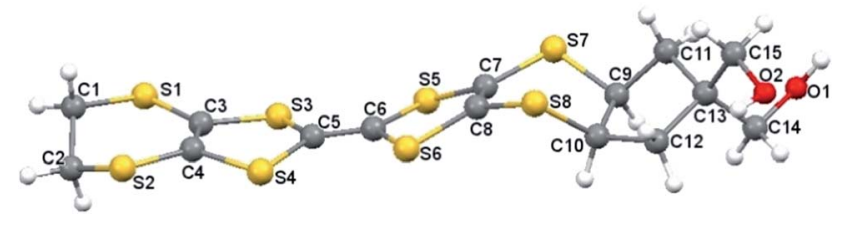

Fig. 5 Molecular structure of $\mathrm{H} 2$ with atomic labelling scheme.

The donors are hydrogen bonded into layers which lie at $63^{\circ}$ to the $c$-axis with four donors contributing one hydroxyl group to a hydrogen bonded square motif of oxygen atoms, similar to that observed in the structure of $\mathbf{H 1}$, Fig. 6 a.

The $\mathrm{O} \cdots \mathrm{O}$ distances are 2.701(7) and 2.762(8) $\AA$, and there are short $\mathrm{S} \cdots \mathrm{S}$ contacts of 3.323(3), 3.523(3) and 3.525(3) A between donors. The unit cell contains eight successive layers, with no $\pi$ stacking of donors and just a few short $S \cdots S$ contacts in the range of 3.562(3) to 3.737(3) A, Fig. 6b. Unfortunately, establishing suitable conditions for the growth of suitable single crystals from a diastereoisomeric mixture proved particularly challenging and thus no suitable crystals of $\mathbf{H 3}$ have been obtained to date.

\section{$O$-Acetyl-protected donor 13}

The crystal structure of the $O$-acetyl-protected $\mathbf{1 3}$ was determined to assess how the larger acetyl substituents as well the absence of the $\mathrm{OH}$ groups affect the packing arrangement of the BEDT-TTF derivatives. Single crystals of $\mathbf{1 3}$ were obtained via slow diffusion of diethyl ether into a $\mathrm{CH}_{2} \mathrm{Cl}_{2}$ solution of the protected donor.

The donor crystallises in the triclinic space group $P \overline{1}$ with two independent molecules in the asymmetric unit. In contrast to the bowed geometries of the previously described donors, this molecule adopts a planar configuration for the central organosulfur residue with only small torsion angles about the two dithiole $S \cdots S$ vectors of 4.8 and $5.3^{\circ}$, Fig. 7 . The flexibility
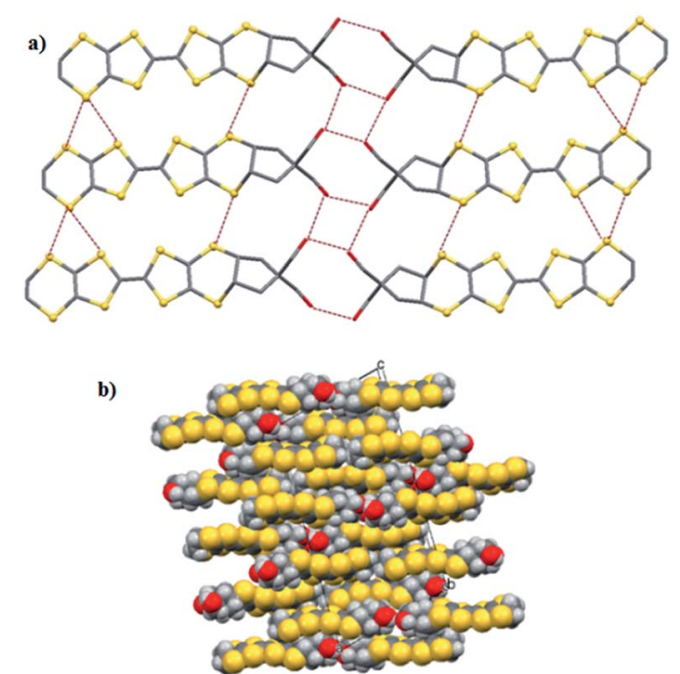

Fig. 6 (a) Crystal packing arrangement of molecules of $\mathrm{H} 2$ into layers showing $\mathrm{S} \cdots \mathrm{S}$ and $\mathrm{H}$-bonding interactions as red dashed lines; (b) view down the $b$-axis with the donor layers running horizontally. $\mathrm{H}$-atoms are omitted for clarity. 


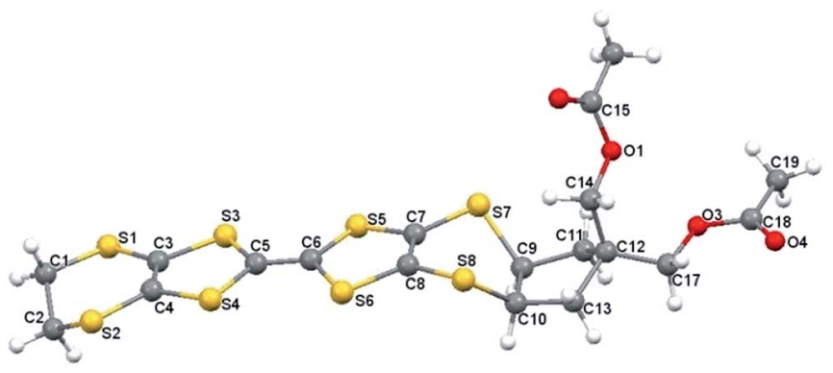

Fig. 7 Molecular structure of 13 with atomic labelling scheme.

about these $S \cdots S$ vectors is a feature of this class of molecules in their neutral states. The molecules are packed in centrosymmetric pairs, with a dithiole group of one donor lying over the central double bond of the other and vice versa, which allows a pair of splayed acetyl groups to extend beyond each end of the pair. The pairs are packed in columns in the $b c$ plane with the long molecular axes at $c a .45^{\circ}$ to the $b$-axis and significantly offset to accommodate the two acetate groups resulting in no short $\pi$-stacking interactions, Fig. 8a. However, there are four short edge-to-edge $\mathrm{S} \cdots \mathrm{S}$ contacts between donors in adjacent columns in the range of 3.3772(6)-3.5881(5) $\AA$, Fig. 8b. For comparison, a summary of the $\mathrm{S} \cdots \mathrm{S}$ contacts and H-bonding interactions in all five structures is presented in Table 2.

Attempts were made to oxidize the donors with iodine and to characterize the molecular structures of the resulting charge transfer salts by X-ray crystallography. Following this strategy we were successful in finding suitable conditions for the growth of suitable single crystals of two radical cation salts, 18 and 19.

Radical cation salts $\left[(\mathrm{H1})^{+\cdot} \mathrm{I}_{3}{ }^{-}\right] \cdot 0.5 \mathrm{I}_{2}(18)$ and $(\mathrm{HMET})^{+\cdot} \mathrm{I}_{3}$

BEDT-TTF forms radical cation salts readily with iodine, affording a number of different stoichiometries and polymorphs that all contain triiodide anions and in some cases also

a)
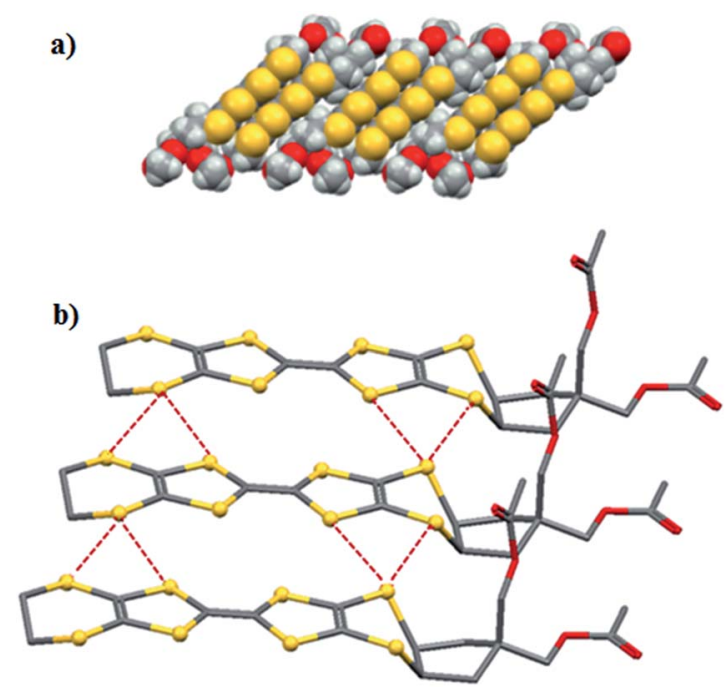

Fig. 8 (a) Crystal packing of centrosymmetrically related pairs of molecules of 13; (b) S...S contacts between adjacent columns of 13 shown as red dashed lines. $\mathrm{H}$-atoms are omitted for clarity.
Table 2 Summary of molecular interactions in the crystal structures of the neutral donors $\mathrm{H} 1, \mathrm{H} 2$ and 13 and the radical cation salts 18 and 19

\begin{tabular}{|c|c|c|c|c|}
\hline Donor & $\begin{array}{l}\text { Dimer } \\
\text { S } \cdots S(\AA)\end{array}$ & 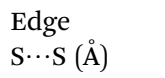 & $\mathrm{D} \cdots \mathrm{A}(\AA)$ & $\mathrm{S} \cdots \mathrm{I}(\AA)$ \\
\hline H1 & $\begin{array}{l}3.5067(8) \\
3.6065(8)\end{array}$ & $\begin{array}{l}3.4121(8) \\
3.5067(8) \text { to } \\
3.595(1)\end{array}$ & $\begin{array}{l}2.673(2) \\
3.727(2)\end{array}$ & - \\
\hline H2 & - & $\begin{array}{l}3.323(3) \\
3.523(3) \\
3.525(3)\end{array}$ & $\begin{array}{l}2.701(7) \\
2.762(8)\end{array}$ & - \\
\hline 13 & - & $\begin{array}{l}3.3772(6) \text { to } \\
3.5881(5)\end{array}$ & - & - \\
\hline 18 & $\begin{array}{l}3.352(4) \\
3.462(4) \\
3.592(5)\end{array}$ & $3.572(4)$ & $2.87(2)$ & $3.639(5)$ to $3.648(2)$ \\
\hline 19 & $\begin{array}{l}3.365(5) \\
3.394(6) \\
3.667(6)\end{array}$ & $3.427(6)$ & & $3.604(4)$ to $3.742(5)$ \\
\hline
\end{tabular}

neutral iodine molecules. ${ }^{31}$ Previous studies have revealed that the triiodide salts of hydroxyl-substituted donors tend to have $1: 1$ stoichiometries with the "soft" triiodide anions preferring to lie closer to sulfur atoms than to hydroxyl groups. ${ }^{13 b, 32}$ Single crystals of 18 were prepared via the slow diffusion of an iodine solution into a solution of $\mathbf{H 1}$ in dichloromethane. X-ray crystallography reveals that in contrast to the molecular structure of the neutral donor, there is one unique radical cation in the asymmetric unit whose 7-membered ring adopts a chair conformation, Fig. 9. After oxidation, the BEDT-TTF derivatives adopt a more planar conformation which can be clearly seen when comparing the molecular structures of donor $\mathbf{H 1}$ before and after oxidation, Fig. 10 and Table 3.

The C-S bond lengths (1.721(9)-1.742(9) $\AA$ ) and $\mathrm{C}=\mathrm{C}$ bond lengths $(\mathrm{C} 14=\mathrm{C} 15, \mathrm{C} 16=\mathrm{C} 17, \mathrm{C} 18=\mathrm{C} 19$ are 1.361(13), 1.387(14) and 1.359(13) A, respectively) are in good agreement with those observed in other BEDT-TTF ${ }^{+\cdot}$ charge transfer salts. ${ }^{33}$ For clarity, selected bond lengths of molecule $\mathbf{B}$ of the neutral donor $\mathbf{H} 1$ and its oxidized counterpart [ $[\mathrm{H} 1]^{+\cdot}$ in $\mathbf{1 8}$ are compared in Table 3. As expected, the $\mathrm{C}-\mathrm{S}$ bond lengths of the donor decrease upon oxidation by $c a .0 .035 \AA$ and the central $\mathrm{C}=\mathrm{C}$ bond shows the most change, being lengthened by $c a .0 .04 \AA{ }^{3.3 b}$

The crystals of $\mathbf{1 8}$ are comprised of centrosymmetric pairs of donor radical cations oriented in a head-to-tail manner surrounded by iodine molecules and a disordered array of triiodide ions corresponding to a formula of $\left[(\mathrm{H} 1) \mathrm{I}_{3}\right] \cdot 0.5 \mathrm{I}_{2}(\mathbf{1 8})$ that is further supported by the elemental analysis data, Fig. 11. The

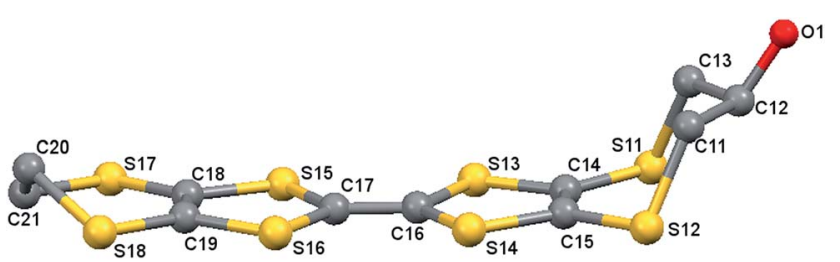

Fig. 9 Molecular structure of $[\mathrm{H} 1]^{+\cdot}$ with atomic labelling scheme. $\mathrm{H}$ atoms are omitted for clarity. 


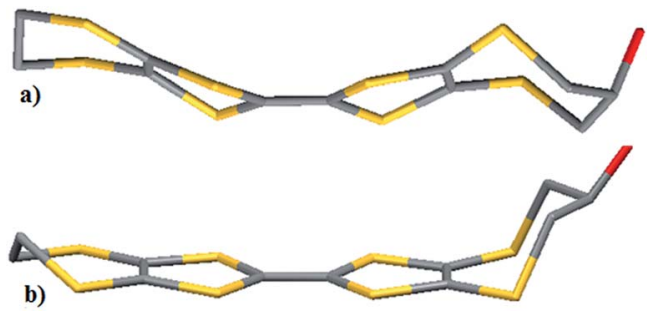

Fig. 10 The molecular structure of donor $\mathrm{H} 1$ (a) when neutral and (b) after oxidation to the radical cation. $\mathrm{H}$-atoms are omitted for clarity.

disordered triiodide anions fill the space between iodine molecules in the $c$-direction between adjacent cells, and also fill channels running in the $a$-direction throughout the crystal. The organosulfur heterocycles of the cation pair lie opposite each other with eight $\mathrm{S} \cdots \mathrm{S}$ contacts; two each of 3.352(4), 3.365(4) and 3.462(4) $\AA$ and a longer one of 3.592(5) $\AA$, Fig. 12a (red dashed lines). S $\cdots \mathrm{S}$ contacts of 3.572(4) $\AA$ between dimer pairs are shown as blue dashed lines in Fig. 12a.

The iodine molecules lie between the donor cation pairs with

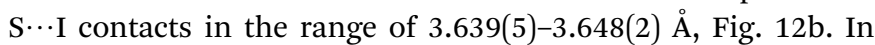
contrast to the crystal structure of the neutral donor there are no $\mathrm{H}$-bonded square motifs, but there are hydrogen bonds between the cation pairs located "end to end" $(\mathrm{O} \cdots \mathrm{O}=2.87(2) \AA)$.

Single crystals of the radical cation salt of HMET 19, were grown via the slow diffusion of an acetonitrile solution of iodine into a THF solution of the donor. The compound crystallizes in the monoclinic space group $I 2 / c$ with 1.5 independent donors and 1.5 tri-iodide anions in the asymmetric unit. The molecular structure of the donors is shown in Fig. 13.

Once again the donors adopt a more planar conformation after oxidation, with the first donor packing as part of a centrosymmetric pair stabilized by four sets of face-to-face $\mathrm{S} \cdots \mathrm{S}$ contacts between 3.365(5) and 3.667(6) ̊, Table 2. The second donor acts as a spacer where its sulfur atoms participate in edge-to-edge contacts $(3.427(6) \AA)$, connecting it to the dimers both above and below it in a stack that propagates along the $b$-axis, Fig. 14 .

Table 3 Comparison of selected $\mathrm{C}-\mathrm{C}, \mathrm{C}=\mathrm{C}$ and $\mathrm{C}-\mathrm{S}$ bond lengths in $\mathrm{H} 1$ and $[\mathrm{H} 1]^{\cdot+}$ in 18

\begin{tabular}{|c|c|c|c|}
\hline \multicolumn{2}{|l|}{ H1 } & \multicolumn{2}{|l|}{$[\mathrm{H} 1]^{\cdot+}$} \\
\hline Bond & Distance $(\AA)$ & Bond & Distance $(\AA)$ \\
\hline C5-C6 & $1.345(3)$ & C16-C17 & $1.387(14)$ \\
\hline C6-S5 & $1.7571(19)$ & C16-S13 & $1.721(9)$ \\
\hline C6-S6 & $1.7578(19)$ & C16-S14 & $1.713(9)$ \\
\hline C5-S3 & $1.758(2)$ & C17-S15 & $1.727(9)$ \\
\hline C5-S4 & $1.7607(19)$ & C17-S16 & $1.728(9)$ \\
\hline S5-C7 & $1.7609(19)$ & S13-C14 & $1.732(11)$ \\
\hline S6-C8 & $1.7611(19)$ & S14-C15 & $1.735(9)$ \\
\hline S3-C3 & $1.761(2)$ & S15-C18 & $1.742(9)$ \\
\hline S4-C4 & $1.776(2)$ & S16-C19 & $1.737(9)$ \\
\hline C7-C8 & $1.341(3)$ & C14-C15 & $1.361(13)$ \\
\hline $\mathrm{C} 3-\mathrm{C} 4$ & $1.345(3)$ & C18-C19 & $1.359(13)$ \\
\hline
\end{tabular}

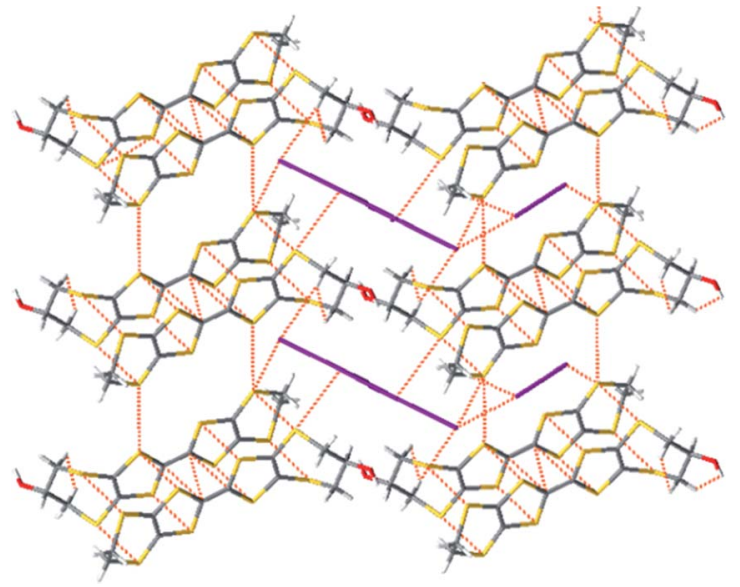

Fig. 11 Crystal packing of 18 showing the head-to-tail arrangement of donor cations in dimers that form channels which accommodate the $\mathrm{I}_{3}{ }^{-}$counterions and neutral $\mathrm{I}_{2}$ molecules.

Further examination of the crystal packing reveals that the stacks are interspersed by two sets of tri-iodide counter anions. The first set occupies the spaces between the donor molecules and the second run perpendicular to the stacks of donors along the $a$-axis, Fig. 15. The former anion is well-located but the second $\mathrm{I}_{3}{ }^{-}$anion is poorly located indicative of some static or dynamic disorder. As is common for these systems, the packing arrangement is further stabilized by a series of short $\mathrm{S} \cdots \mathrm{I}$
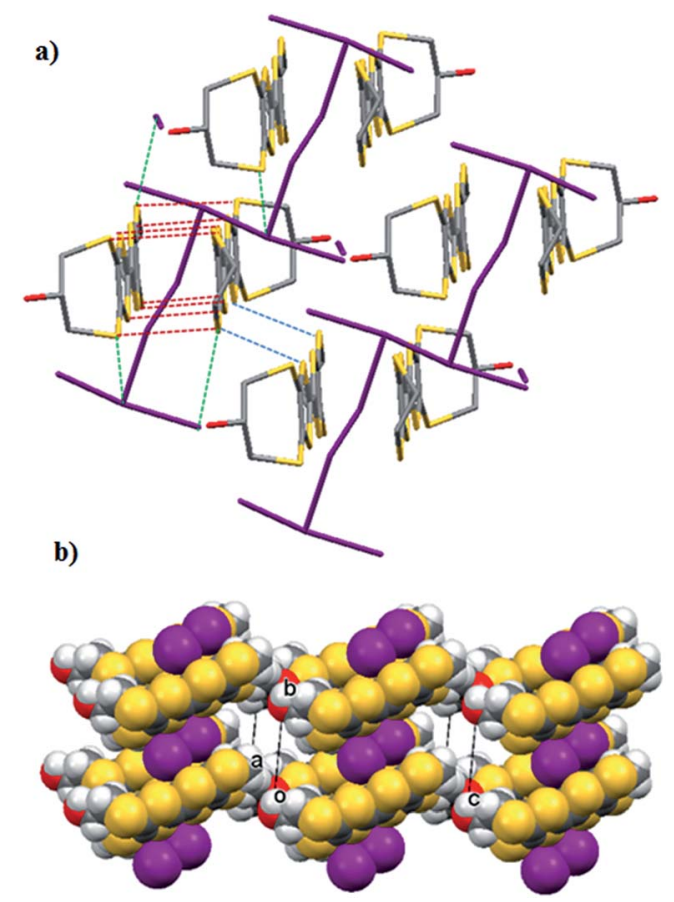

Fig. 12 (a) Crystal packing of 18; short S...S contacts between dimers are shown in red; $S \cdots \mid$ contacts are shown in green and inter-dimer S...S contacts are shown in blue. (b) Crystal packing of the oxidized donors with the disordered triiodides removed showing the neutral iodine molecules organized in the channels between stacks of dimers. $\mathrm{H}$-atoms are omitted for clarity. 

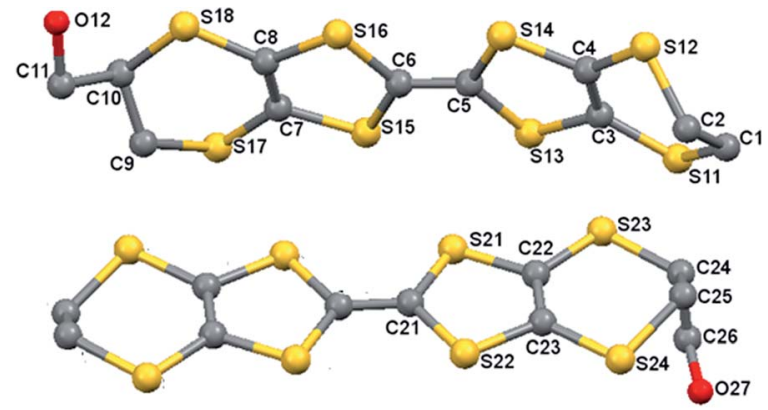

Fig. 13 Molecular structure of the two independent molecules of [HMET] $^{+\cdot}$ in 19 with the appropriate atomic labelling scheme. For clarity, only one orientation of the disordered side chains is shown. $\mathrm{H}$ atoms are omitted for clarity.

contacts that range from 3.604(4) to $3.742(5) \AA$, Fig. 15. Interestingly, this arrangement is different from crystal packing of the HMET radical cation in the charge transfer salt $(\mathrm{HMET})\left[\mathrm{Cr}(\mathrm{NAOP})(\mathrm{NCS})_{2}\right]\left(\mathrm{NAOP}^{2-}=N, N^{\prime}-(1,2-\right.$ phenylenebis(nitrilomethylidyne))bis(2-naphthoate)). ${ }^{33}$

In the latter case, the radical cations are organized into pairs that are isolated from each other, but this may in part be due to the bulky nature of the complex anions in the crystal structure. Further comparison of the two HMET charge transfer salts reveals that for both compounds the hydroxylmethyl side chains are extremely disordered making the refinement of their crystal structures problematic. This may also explain why suitable conditions for the growth of single crystals of the neutral HMET donor have proven elusive to date. More importantly, this also reveals that in certain cases unsymmetrically substituted donors struggle to pack efficiently in the solid state, which may have a negative impact on their electron mobilities. In order to investigate this further we investigated the electronic properties of this family of donors both in solution and after fabrication into polymeric thin films.

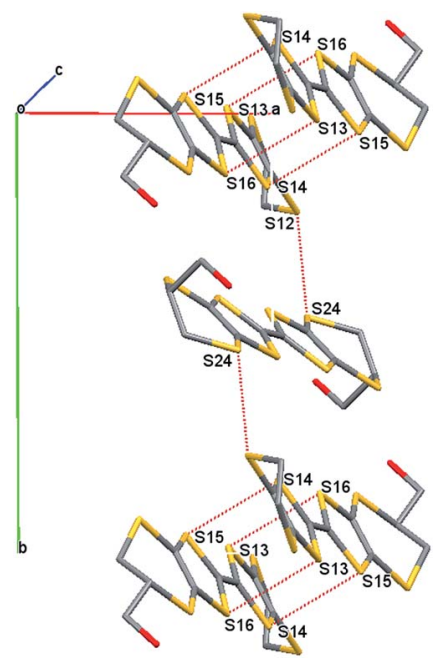

Fig. 14 View down the c-axis showing one stack of HMET donors in 19. S..S contacts are shown as red dashed lines. $\mathrm{H}$-atoms are omitted for clarity.

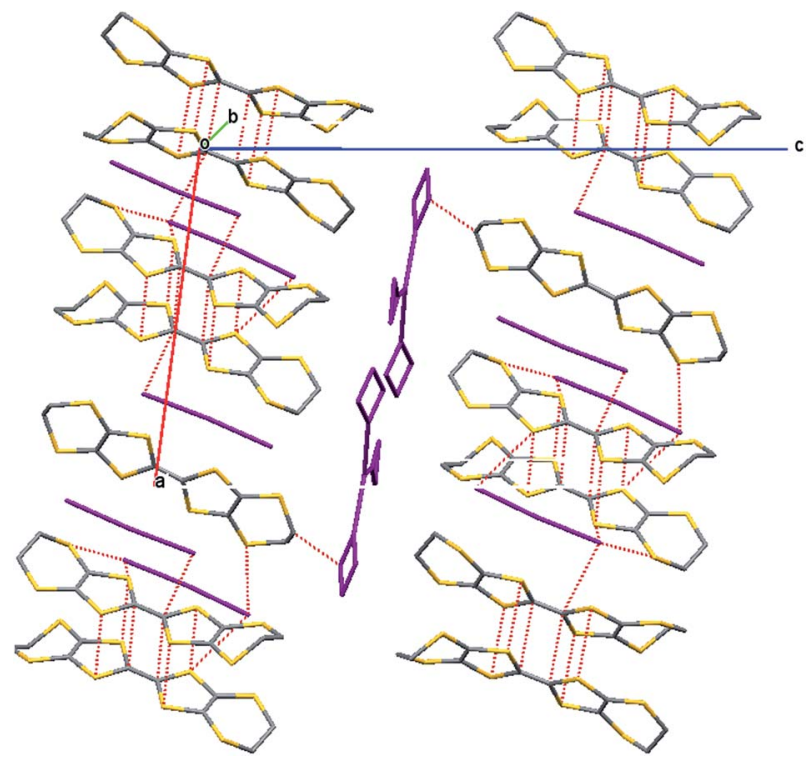

Fig. 15 Crystal packing of $[\mathrm{HMET}]^{+\cdot} \mathrm{I}_{3}^{-}$. View down the $b$-axis showing the arrangement of the donors and the iodide anions. S $\cdots S$ and $S \cdots I$ contacts are shown as red dashed lines. The disordered hydroxymethyl side chains of the donors and the $\mathrm{H}$-atoms are omitted for clarity.

\section{Electrochemical properties}

The redox potentials of H1-H3 and HMET 2 were investigated by cyclic voltammetry. The results are summarized in Table 4 , together with that of BEDT-TTF for comparison.

For donor $\mathbf{H} 2$ which had poor solubility in $\mathrm{CH}_{2} \mathrm{Cl}_{2}$, the redox properties were measured in THF. All donors show two reversible single-electron redox processes assigned to the formation of the radical cation and dication respectively. The calculated HOMO densities of $\mathbf{H 1}$ and $\mathbf{H 2}$ are similar. The HOMO density is high on the sulfur atoms of the TTF core, but negligible on the sulfur atoms of the outer rings as well as their substituents (Fig. 16).

Comparing the energies of the two HOMOs it is apparent that $\mathbf{H 1}$ is slightly higher in energy which is consistent with the electrochemistry data suggesting that it might be slightly easier to oxidize, Fig. 16.

\section{Thin film studies on $\mathbf{H 3}$}

Given the compromised solubilities of $\mathbf{H 1}$ and $\mathbf{H 2}$ in comparison with HMET 2, we proposed to introduce a longer alkyl side

Table 4 Half-wave redox potentials for $\mathrm{H} 1-\mathrm{H} 3$ and HMET 2 vs. Ag/ $\mathrm{AgCl}$ in $\mathrm{CH}_{2} \mathrm{Cl}_{2}$ or THF with $0.1 \mathrm{Mn}-\mathrm{Bu}_{4} \mathrm{NPF}_{6}$ as the supporting electrolyte scan speed $\left(100 \mathrm{mV} \mathrm{s}^{-1}\right)$

\begin{tabular}{|c|c|c|c|c|}
\hline \multirow[b]{2}{*}{ Compound } & \multicolumn{2}{|c|}{$E_{1}{ }^{1 / 2} / \mathrm{V}$} & \multicolumn{2}{|c|}{$E_{2}{ }^{1 / 2} / \mathrm{V}$} \\
\hline & THF & $\mathrm{CH}_{2} \mathrm{Cl}_{2}$ & THF & $\mathrm{CH}_{2} \mathrm{Cl}_{2}$ \\
\hline BEDT-TTF & 0.68 & 0.48 & 0.83 & 0.89 \\
\hline H1 & 0.70 & 0.51 & 0.86 & 0.91 \\
\hline H2 & 0.72 & - & 0.87 & - \\
\hline H3 & 0.74 & 0.53 & 0.90 & 094 \\
\hline HMET 2 & 0.69 & 0.51 & 0.85 & 0.91 \\
\hline
\end{tabular}




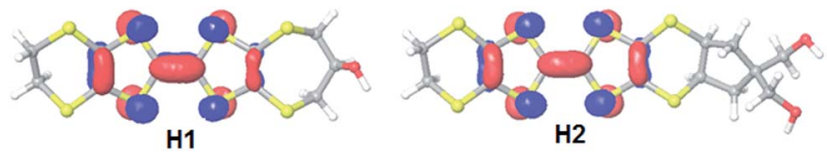

Fig. 16 The HOMO coefficients on $\mathrm{H} 1$ and $\mathrm{H} 2$ (DFT B3LYP/6$31 \mathrm{G}(\mathrm{d}))^{20,21}$ The $\mathrm{HOMO}$ energies are calculated to be -4.93 and -4.95 $\mathrm{eV}$ respectively.

chain into the BEDT-TTF derivative to target the preparation of a more soluble donor for fabrication into thin films. As expected, the particularly good solubility of $\mathbf{H 3}$ in organic solvents made this donor an ideal candidate to establish synthetic protocols for the preparation and study of polymer-blend thin films. Two sets of thin films of $\mathbf{H 3}$ with a thickness of $\sim 27 \mathrm{~nm}$ were first prepared on (i) unmodified and (ii) OTS modified Si wafer substrates. The films were then doped with iodine vapour from an $\mathrm{I}_{2} / \mathrm{CH}_{2} \mathrm{Cl}_{2}$ solution. The specific conductivities and resistivities of these films were then determined and the results are summarized in Table 5. Interestingly, for the doped film of H3 on unmodified substrate, the conductivity was 3 times higher than the $2 \%$ composite films prepared from the thiophene appended BEDT-TTF donor $\mathbf{1 .}^{\mathbf{1 4}}$

FET characterization of doped films comprised of a $1: 1$ weight ratio of $\mathbf{H 3}$ relative to polystyrene (PS) deposited on an unmodified silica wafer substrate showed $I_{\mathrm{DS}}-V_{\mathrm{DS}}$ curves of ohmic and linear properties consistent with quasiconducting behaviour and all the $I-V$ curves overlapped with each other when the gate voltage was changed from +10 to $-40 \mathrm{~V}$ in $10 \mathrm{~V}$ intervals (Fig. 17a).

In contrast, un-doped films of $\mathbf{H 3} / \mathrm{PS}$ gave rise to the $I_{\mathrm{DS}}-V_{\mathrm{DS}}$ plots with profiles shown in Fig. 17b, consistent with an insulating material. From these results we can conclude that iodine vapour doping of the polymer blend film of the donors on $\mathrm{Si}$ wafer substrates produces continuous conducting-like layers. A device was then fabricated from a thin film of $\mathbf{H 3}$ as follows: an $n$-doped Si wafer with a $110 \mathrm{~nm}$ thermally grown silicon dioxide layer (capacitance of $32 \mathrm{nF} \mathrm{cm} \mathrm{cm}^{-2}$ ) was used as the substrate. Semiconductor films were then deposited by spin coating $1 \mathrm{wt} \%$ of chlorobenzene solution of the donor onto octyltrichlorosilane (OTS) modified and unmodified substrates, respectively, at $1000 \mathrm{rpm}$ for $45 \mathrm{~s}$. Gold source and drain electrodes were then deposited over the substrate by vacuum deposition methods through a shadow mask with various channel lengths and widths, Fig. 18.
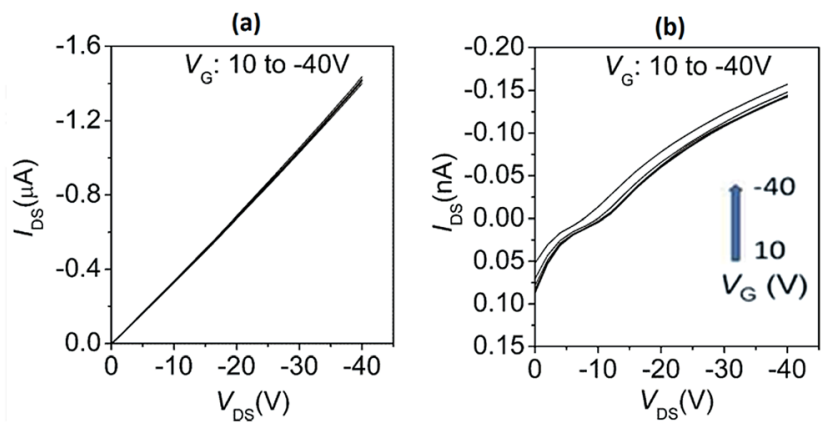

Fig. 17 Drain current versus drain voltage as a function of gate voltage for a device based on (1:1) donor/PS blend films on unmodified $\mathrm{Si}$ wafer substrate at room temperature. (a) $\mathrm{I}_{2}$-doped H3/PS film; (b) undoped $\mathrm{H} 3 / \mathrm{PS}$ film (the gate voltage was changed from 10 to $-40 \mathrm{~V}$ in $10 \mathrm{~V}$ intervals).

Unfortunately, no field effect was observed for the device which we propose is either due to (i) structural defects in the polycrystalline film at least in part due to a disorder of the side chains as observed in the radical cation salts of the closely related HMET donors, or (ii) to a charge trapping effect mediated by the hydroxyl substituents of the donors which is already known to seriously compromise the OFET properties of films fabricated from hydroxyl functionalized polymers. ${ }^{34}$

In order to study the electronic properties of the polymer blend thin-films by Vis-NIR spectroscopy, a surface conducting polystyrene (PS) film deposited on a glass substrate was prepared applying a two-step reticulate doping technique. ${ }^{24,25,35}$ Films comprising $2 \mathrm{wt} \%$ of $\mathbf{H 3}$ donor in a PS composite were exposed to iodine vapour from a $\mathrm{I}_{2} / \mathrm{CH}_{2} \mathrm{Cl}_{2}$ solution $(0.1 \mathrm{~g} / 20$ $\mathrm{mL}$ ). Such treatment results in the deposition of a continuous network containing (H3) $)_{x}$-(polyiodides) $y$ onto the surface layer of the polystyrene films. ${ }^{14}$ It should be noted that since the real thickness of the conducting layer is unknown the exact resistivity and specific conductivity of the network in the films cannot be determined. The un-doped film exhibited insulating behavior with conductivities comparable to the glass substrate. For the doped film, if we assume the conducting layer thickness to be approximately the same as the thickness of the polymer film $(20 \mu \mathrm{m})$, a resistivity $(\rho)$ of $200 \Omega \mathrm{cm}$ and conductivity $(\sigma)$ of $5 \times 10^{-3} \mathrm{~S} \mathrm{~cm}^{-1}$ was estimated, suggesting that there is an efficient pathway for electron mobility. We also can A comparison of Vis-NIR spectra for doped and undoped films of $\mathbf{H 3}$ in a polystyrene matrix is shown in Fig. 19.

Table 5 Specific conductivities and resistivities of thin films of $\mathrm{H} 3$ deposited on $\mathrm{Si}$

\begin{tabular}{lcc}
\hline Material & Specific conductivity S cm & Resistivity \\
\hline H3/PS OTS modified Si substrate, undoped & $3.7 \times 10^{-8}$ & $2.7 \times 10^{7}$ \\
H3/PS modified OTS Si substrate I 2 doped & $1.1 \times 10^{-4}$ & $9 \times 10^{3}$ \\
H3/PS unmodified Si substrate, undoped & $5.0 \times 10^{-8}$ & $2.0 \times 10^{7}$ \\
H3/PS unmodified OTS Si substrate $\mathrm{I}_{2}$ doped & $2.2 \times 10^{-5}$ & $4.5 \times 10^{4}$ \\
H3/2\% PS glass substrate I 2 doped & $5 \times 10^{-3}$ & 200 \\
Thiophene donor 1/2\% PS glass substrate $\mathrm{I}_{2}$ doped $^{14}$ & $3.5 \times 10^{-5}$ & $2.8 \times 10^{4}$
\end{tabular}




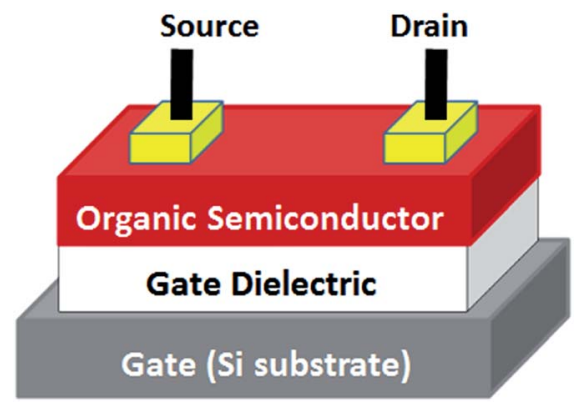

Fig. 18 Schematic diagram of the OTFT device configuration.

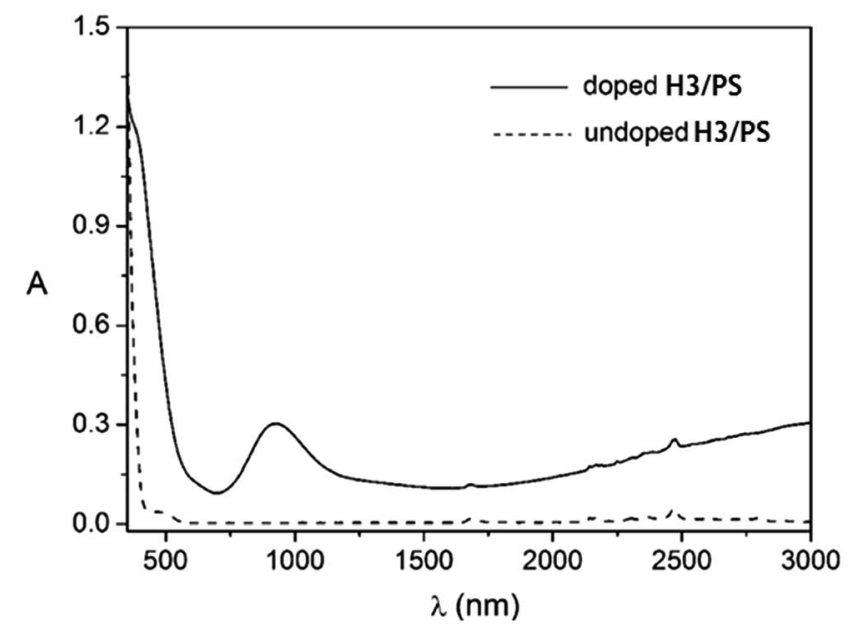

Fig. 19 Vis-NIR spectra of un-doped and doped films on glass substrates for a $2 \mathrm{wt} \%$ ratio of $\mathrm{H} 3$ relative to $\mathrm{PS}$

The absorption bands at 950 and $3000 \mathrm{~nm}$ are assigned to mixed-valence CT states and are consistent with the realization of a $\pi$-conducting network that facilitates conductivity. ${ }^{36}$ In contrast to the recently characterized PS composites of thiophene appended BEDT-TTF derivatives, no broad absorption band between 1250 and $1500 \mathrm{~nm}$ was observed, ruling out the presence of any fully oxidized salts in the polymer matrix. ${ }^{\mathbf{1 4}}$

\section{Conclusion}

We have prepared and characterized three new hydroxylsubstituted BEDT-TTF derivatives, together with an acetyl intermediate and two radical cation salts. Our studies reveal (i) several types of short contacts including H-bonding. $\mathrm{S} \cdots \mathrm{S}$ and $\mathrm{S} \cdots \mathrm{I}$ interactions organize the donors and acceptors in the solid state and that the importance of hydrogen bonding in organizing the donors in their neutral state is overridden by $\mathrm{S} \cdots \mathrm{S}$ and $S \cdots$ I interactions, which are likely responsible for the onset of conductivity on doping; (ii) hydroxyl groups improve the electron transport properties of the thin films deposited on glass substrates and (iii) the unsymmetrical derivatives are susceptible to disorder in the solid state which may compromise their electron transport properties. Donor H3 was successfully incorporated into two sets of polymeric thin films deposited on either silica or glass substrates. Both types of films displayed quasi-conducting properties upon doping with $\mathrm{I}_{2}$. The lack of any OFET response for devices fabricated from thin films deposited onto silica can be primarily attributed to the hydroxyl substituents of the donors combining with water molecules acting to trap the charges at the interface of the device between the semiconductor and the dielectric media. This phenomenon is not unique to this system; trap states in organic semiconductors are currently the subject of intense study and are known to severely compromise the performance of OFET devices. ${ }^{34}$ Although the hydroxyl donors studied here are clearly not suitable candidates for organic field effect transistors, they do afford thin films whose electronic properties and solubilities can be chemically tuned and thus may yet lend themselves to applications within the field of organic electronics.

\section{Acknowledgements}

Financial support from NSERC (Discovery, MP and JMR; Strategic Supplemental, MP), CRC (Tier II MP; Tier I JMR), CFI and ORF (New Opportunities, MP), Brock University (International Seed Funds MP) (Ministry of Ontario, Early Researchers Award, MP). Nottingham Trent University is gratefully acknowledged for a sabbatical period (JDW). JDW thanks the EPSRC UK National Mass Spectrometry Facility at Swansea University for data. We also gratefully acknowledge the XRCC for access to facilities and expertise to carry out the thin film and OFET part of this study.

\section{References}

1 (a) F. Wudl, G. M. Smith and E. J. Hufnael, J. Chem. Soc., Chem. Commun., 1970, 1453; (b) S. Hunig, G. Kiesslich, D. Scheutzow, D. Zharadnik and P. Carsky, Int. J. Sulfur Chem., 1971, (part C), 109; (c) M. Nazario, Chem. Commun., 2013, 49, 7025.

2 (a) M. R. Bryce, J. Mater. Chem., 2000, 10, 589; (b) J. L. Segura and N. Martın, Angew. Chem., Int. Ed., 2001, 40, 1372; (c) M. Bendikov, F. Wudl and D. F. Perepichka, Chem. Rev., 2004, 104, 4891; (d) P. Batail, Chem. Rev., 2004, 104, 4887; (e) E. Doni and J. A. Murphy, Chem. Commun., 2014, 50, 6073.

3 (a) D. Canevet, M. Sallé, G. Zhang, D. Zhang and D. Zhu, Chem. Commun., 2009, 2245; (b) V. A. Azov, J. Cordes, D. Schfeuler, T. Boeckmann, D. Marcus and L. Nikos, J. Org. Chem., 2014, 79, 1174; (c) T. Avellini, H. Li, A. Coskun, E. Barin, A. Trabalsi, A. Basvray, N. Ashish, K. Sanjeev, A. Credi, S. Silvi and F. J. Stoddart, Angew. Chem., Int. Ed., 2012, 51, 1611; (d) C. Simao, M. Mas Torrent, J. CasadoMontenegro, F. Oton, J. Vecciana and C. Rovira, J. Am. Chem. Soc., 2011, 133, 13256; (e) C. P. Collier, E. W. Wong, M. Belohradsky, F. M. Raymo, J. F. Stoddart, P. J. Kuekes, R. S. Williams and J. R. Heath, Science, 1999, 285, 391.

4 (a) J. Xiang, L. Long, W. Liu, J. E. Boves, Z. Yu-Xang and J.-L. Zuo, Tetrahedron Lett., 2013, 54, 1998; (b) M. Falk, V. Andoralov, M. Silow, M. D. Toscano and S. Shleev, Anal. Chem., 2013, 85, 6342; (c) G. Yang, Z. Chong-an, G. Zhang, J. Zhang, J. Xiang, D. Zhang and D. Zhu, Adv. Funct. Mater., 
2013, 23, 1671; (d) M. Hardouin-Lerouge, B. Chesneau, M. Allain and P. Hudhomme, J. Org. Chem., 2012, 77, 2441; (e) W. Wu, Y. Liu and D. Zhu, Chem. Soc. Rev., 2010, 39, 1489. 5 (a) F. Pop, S. Laroussi, T. Cauchy, C. Gomez-Garcia, J. Carlos, J. D. Wallis and N. Avarvari, Chirality, 2013, 25, 466; (b) H. Muller, S. Fiedler, M. Saad and C. Riekel, Synth. Met., 1997, 86, 1885; (c) T. L. Li and R. Giasson, J. Am. Chem. Soc., 1994, 11, 9890; (d) H. Akutsu, J.-I. Nakatsuji and S. S. Turner, Dalton Trans., 2013, 42, 16351; (e) L. Martin, P. Day, S. A. Barnett, D. A. Tocher, P. N. Horton and M. B. Hursthouse, CrystEngComm, 2008, 10, 192; (f) T. Enoki and A. Miyazaki, Chem. Rev., 2004, 104, 5449.

6 (a) E. Laukhina, R. Pfattner, L. R. Ferreras, S. Galli, M. MasTorrent, N. Masciocchi, V. Laukhin, C. Rovira and J. Veciana, Adv. Mater., 2010, 22, 977; (b) E. Laukhina, R. Pfattner, M. Mas-Torrent, C. Rovira, J. Veciana and V. Laukhin, Sens. Transducers J., 2011, 10, 1; (c) H. Alves, A. S. Molinari, H. Xie and A. F. Morpurgo, Nat. Mater., 2008, 7, 574; (d) R. M. Metzger, B. Chen, U. Hopfner, M. V. Lakshmikantham, D. Villaume, T. Kawai, X. Wu, H. Tachibana, T. V. Hughes, H. Sakurai, J. W. Baldwin, C. Hosch, M. P. Cava, L. Brehmer and G. J. Ashwell, J. Am. Chem. Soc., 1997, 119, 10455; (e) D.-Y. Noh, A. G. Willing, Y. C. Han, K.-S. Shin, U. Geiser and H. H. Wang, Chem. Mater., 2004, 16, 4777; (f) H. Dong, X. Fu, J. Liu, Z. Wang and W. Hu, Adv. Mater., 2013, 25, 6158; (g) Organic Electronics: Materials, Manufacturing and Applications, ed. H. Klauk, VCH-Wiley, 2006.

7 (a) B. Mukherjee and M. Mukherjee, Langmuir, 2011, 27, 11246; (b) R. Pfattner, M. Mas-Torrent, I. Bilotti, A. Brillante, S. Milita, F. Liscio, F. Biscarini, T. Marszalek, J. Ulanski and A. Nosal, Adv. Mater., 2010, 22, 4198; (c) X. Gao, W. Qiu, Wenfeng, Y. Liu, G. Yu and D. Zhu, Pure Appl. Chem., 2008, 80, 2405.

8 (a) J. M. Williams, M. A. Beno, H. H. Wang, P. C. W. Leung, T. J. Emge, U. Geiser and K. D. Carlson, Acc. Chem. Res., 1985, 18, 261; (b) P. Day, C. R. Chim., 2003, 6, 301; (c) T. Mori, Bull. Chem. Soc. Jpn., 1998, 71, 2509; (d) T. Mori, H. Mori and S. Tanaka, Bull. Chem. Soc. Jpn., 1999, 72, 179; (e) T. Mori, Bull. Chem. Soc. Jpn., 1999, 72, 2011; (f) T. Mori, Chem. Rev., 2004, 104, 4947.

9 (a) N. Yoshimoto, H. Maehara, Y. Ueda, J. Ni, K. Omote and M. Yoshizawa, Mol. Cryst. Liq. Cryst., 1998, 316, 129; (b) S. Molas, J. Caroa, J. Santiso, A. Figueras, J. Fraxedas, C. Méziére, M. Fourmigué and P. Batail, J. Cryst. Growth, 2000, 218, 399; (c) U. Geiser, H. H. Wang, C. Y. Han and G. A. Willing, NATO Sci. Ser., II, 2004, 139, 217, Organic Conductors, Superconductors and Magnets, 231; (d) K. Kawabata, K. Tanaka and M. Mizutani, Solid State Commun., 1990, 75, 83; (e) M. Kilitziraki, A. J. Moore, M. C. Petty and M. R. Bryce, Thin Solid Films, 1998, 335, 209.

10 (a) V. I. Troitsky, T. S. Berzina, E. Dalcanale and M. P. Fontana, Thin Solid Films, 2002, 405, 276; (b) V. I. Troitsky, E. Stussi, M. Mule and D. De Rossi, Synth. Met., 1993, 60, 111; (c) T. S. Berzina, S. A. Shikin, P. S. Sotnikov, V. I. Troitsky, V. Y. Khodorkovsky,
O. Y. Neilands and G. Pukitis, Top. Mol. Organ. Eng., 1991, 7, 99.

11 H. H. Wang, C. Y. Han, D.-Y. Noh, K.-S. Shin, G. A. Willing and U. Geiser, Synth. Met., 2003, 137, 1201.

12 H. X. Li, D. Q. Zhang, Y. Xu, W. Xu, G. Yu, X. G. Li and D. B. Zhu, Synth. Met., 2001, 123, 385.

13 (a) J.-P. Grifffiths and J. D. Wallis, J. Mater. Chem., 2005, 15, 347; (b) I. Awheda, S. J. Krivickas, S. Yang, L. Martin, M. A. Guziak, A. C. Brooks, F. Pelletier, M. Le Kerneau, P. Day, P. N. Horton, H. Akutsu and J. D. Wallis, Tetrahedron, 2013, 69, 8738; (c) Q. Wang, P. Day, J. P. Griffiths, H. Nie and J. D. Wallis, New J. Chem., 2006, 1790; (d) N. Saygili, R. J. Brown, P. Day, R. Hoelzl, P. Kathirgamanathan, E. R. Mageean, T. Ozturk, M. Pilkington, M. M. B. Qayyum, S. S. Turner, L. Vorwerg and J. D. Wallis, Tetrahedron, 2001, 57, 5015; (e) T. Ozturk, N. Saygili, S. Ozkara, M. Pilkington, C. R. Rice, D. A. Tranter, F. Turksy and J. D. Wallis, J. Chem. Soc., Perkin Trans. 1, 2001, 4, 407.

14 Q. Wang, J. D. Wallis, Y. Wu and M. Pilkington, CrystEngComm, 2014, 16, 10235.

15 A. Ueda, S. Yamada, I. Takayuki, H. Kamo, A. Akiko, R. Kumai, H. Nakao, Y. Murakami, K. Yamamoto and Y. Nishio, J. Am. Chem. Soc., 2014, 136, 12184.

16 (a) G. M. Sheldrick, Acta Crystallogr., Sect. A: Found. Crystallogr., 2008, 64, 112; (b) SAINT, v. 6.02, Bruker AXS Inc., Madison, WI, 1999; (c) APEX-II, Bruker AXS Inc., Madison, Wisconsin, USA.

17 G. M. Sheldrick, SADABS, v. 2.05, University of Göttingen, Germany.

18 (a) CrysAlisPro, Agilent Technologies, Version 1.171.35.15, release 03-08-2011; (b) SHELXTL package for crystal structure solution and refinementBruker AXS Inc., Madison, Wisconsin, USA.

19 (a) A. L. Spek, Acta Crystallogr., Sect. C: Cryst. Struct. Commun., 2015, 71, 9-19; (b) P. van der Sluis and A. L. Spek, Acta Crystallogr., Sect. A: Found. Crystallogr., 1990, 46, 194; (c) A. L. Spek, PLATON, A Multipurpose Crystallographic Tool, Utrecht University, Utrecht, Netherlands, 2005.

20 C. Lee, W. Yang and R. G. Parr, Phys. Rev. B: Condens. Matter Mater. Phys., 1988, 37, 785.

21 Jaguar version 8.0, Schrödinger LLC, New York, NY, 2013.

22 (a) M. Mas-Torrent, E. Laukhina, C. Rovira, J. Veciana, V. Tkacheva, L. Zorina and S. Khasanov, Adv. Funct. Mater., 2001, 11, 299; (b) A. Tracz, J. K. Jeszka, A. Sroczyńska, J. Ulański and T. Pakula, Adv. Mater. Opt. Electron., 1996, 6, 335.

23 W. Wu, Y. Liu and D. Zhu, Chem. Soc. Rev., 2010, 39, 1489. 24 (a) P. Polanowski, A. Tracz, J. Ulański and E. Dormann, Synth. Met., 2000, 109, 235; (b) J. K. Jeszka, A. Tracz, M. Sroczyńska, H. Kryszewski, S. Yamochi, G. Horiuchi, J. Saito and J. Ulański, Synth. Met., 1999, 106, 75; (c) S. Hornchi, H. Yamochi, G. Saito, J. K. Jeszka, A. Tracz, A. Sroczyńska and J. Ulański, Mol. Cryst. Liq. Cryst., 1997, 296, 365; (d) J. K. Jeszka and A. Tracz, Polym. Adv. Technol., 1992, 3, 139. 
25 (a) E. Laukhina, V. Tkacheva, I. Chuev, E. Yagubskii, J. VidalGancedo, M. Mas-Torrent, C. Rovira, J. Veciana, S. Khasanov, R. Wojciechowski and J. Ulanski, J. Phys. Chem. B, 2001, 105, 11089; (b) M. Wiatrowski, E. Dobruchowska, W. Maniukiewicz, U. Pietsch, J. Kowalski, Z. Szamel and J. Ulanski, Thin Solid Films, 2010, 518, 2266; (c) X. K. Gao, W. P. Wu, Y. Q. Liu, W. F. Qiu, X. B. Sun, G. Yu and D. B. Zhu, Chem. Commun., 2006, 2750.

26 R. J. Brown, A. C. Brooks, J.-P. Griffiths, B. Vital, P. Day and J. D. Wallis, Org. Biomol. Chem., 2007, 5, 3172-3182.

27 C. Wang, A. S. Batsanov, M. R. Bryce and J. A. K. Howard, Synthesis, 1998, 1615.

28 G. J. Marshallsay, M. R. Bryce, G. Cooke, T. Jørgensen, J. Becher, C. D. Reynolds and S. Wood, Tetrahedron, 1993, 49, 6849.

29 N. Svenstrup and J. Becher, Synthesis, 1995, 215.

30 J. Broggi, N. Joubert, S. Dez-González, S. Berteina-Raboin, T. Zevaco, S. P. Nolan and L. A. Agrofoglio, Tetrahedron, 2009, 65, 1162.

31 (a) R. P. Schibaeva and E. B. Yagubskii, Chem. Rev., 2004, 104, 5347; (b) M. A. Beno, U. Geiser, K. L. Kostka,
H. H. Wang, K. S. Webb, M. A. Firestone, K. D. Carlson, L. Nunez, M. H. Whangbo and J. M. Williams, Inorg. Chem., 1987, 26, 1912.

32 (a) S.-X. Liu, A. Neels, H. Stoecki-Evans, J. D. Wallis, M. Pilkington and S. Decurtins, Polyhedron, 2005, 23, 1185; (b) L. Martin, M. Guziak and J. D. Wallis, 2015, manuscript in preparation.

33 (a) S. Wang, P. Day, J. D. Wallis, P. N. Horton and M. B. Hursthouse, Polyhedron, 2006, 25, 2583; (b) D. A. Clemente and A. Marzotto, J. Org. Chem., 1996, 6, 941. 34 (a) J. Jang, S. H. Kim, S. Nam, D. S. Chung, C. Yang, W. M. Yun, C. E. Park and J. B. Koo, Appl. Phys. Lett., 2008, 92, 143306; (b) G. Gu, M. G. Kane, J. E. Doty and A. H. Firester, Appl. Phys. Lett., 2005, 87, 243512.

35 E. Laukhina, V. Tkacheva, S. Khasanov, L. Zorina, J. GómezSegura, A. P. D. Pino, J. Veciana, V. Laukhin and C. Rovira, ChemPhysChem, 2006, 7, 920.

36 A. Tracz, J. K. Jeska, J. Ulański, T. Pakula and J. P. Rabe, Synth. Met., 1998, 94, 17. 